UNIVERSIDADE ESTADUAL PAULISTA

FACULDADE DE MEDICINA VETERINÁRIA E ZOOTECNIA

CAMPUS DE BOTUCATU

\title{
ISÓTOPOS ESTÁVEIS NA RASTREABILIDADE DE FARINHA DE ORIGEM ANIMAL NA ALIMENTAÇÃO DE FRANGOS DE CORTE
}

\author{
PRISCILA CAVALCA DE ARAUJO
}

Dissertação apresentada ao Programa de Pós-Graduação em Zootecnia como parte das exigências para obtenção do título de Mestre 
UNIVERSIDADE ESTADUAL PAULISTA

FACULDADE DE MEDICINA VETERINÁRIA E ZOOTECNIA

CAMPUS DE BOTUCATU

\title{
ISÓTOPOS ESTÁVEIS NA RASTREABILIDADE DE FARINHA DE ORIGEM ANIMAL NA ALIMENTAÇÃO DE FRANGOS DE CORTE
}

\author{
PRISCILA CAVALCA DE ARAUJO
}

ORIENTADOR: Prof. Dr. JOSÉ ROBERTO SARTORI CO-ORIENTADOR Dra. VALQUÍRIA CAÇÃO DA CRUZ

Dissertação apresentada ao Programa de Pós-Graduação em Zootecnia como parte das exigências para obtenção do título de Mestre 
FICHA CATALOGRÁFICA ELABORADA PELA SEÇÃO TÉCNICA DE AQUISIÇÃO E TRATAMENTO DA INFORMAÇÃO - SERVIÇO TÉCNICO DE BIBLIOTECA E DOCUMENTAÇÃO - UNESP - FCA - LAGEADO - BOTUCATU (SP)

Araujo, Priscila Cavalca, 1981-

A663i Isótopos estáveis na rastreabilidade de farinha de origem animal na alimentação de frangos de corte / Priscila Cavalca Araujo. - Botucatu : [s.n.], 2010.

vi, $49 \mathrm{f}$. : foto color., gráfs., tabs.

Dissertação (Mestrado) - Universidade Estadual Paulista, Faculdade de Medicina Veterinária e Zootecnia, Botucatu, 2010

Orientador: José Roberto Sartori

Inclui bibliografia.

1. Farinha de vísceras. 2. Carbono-13. 3. Nitrogênio-15. 4. Certificação. I. Sartori, José Roberto. II. Universidade Estadual Paulista "Júlio de Mesquita Filho" (Campus de Botucatu). Faculdade de Medicina Veterinária e Zootecnia. III. Título. 
"De tudo ficam três coisas:

a certeza de que estamos começando, a certeza que é preciso continuar e a certeza de que podemos ser interrompidos antes de terminar

Fazer da interrupção um novo caminho, da queda um passo de dança, do medo uma escola, do sonho uma ponte, da procura um encontro.

E assim terá valido a pena." 


\section{DEDICATÓRIA}

Deus em primeiro lugar, sempre.

Aos meus pais, Fátima e José Carlos, pelo incentivo, tamanha confiança e amor. Em especial a minha mãe que me proporcionou a possibilidade de estudar e por ser o reflexo de uma vida dedicada a sua profissão, sempre com caráter, humildade e amor por tudo que faz.

Aos meus irmãos, Carla e Rodrigo, pelo apoio, amizade e amor.

Aos meu sobrinhos pelos momentos de alegria. 


\section{AGRADECIMENTOS}

Meus sinceros agradecimentos,

Ao Prof. Dr. José Roberto Sartori, pela oportunidade de novos caminhos, pelos ensinamentos e orientação.

À Dra. Valquíria Cação da Cruz por sua co-orientação, atenção disponibilizada no auxílio em todas as fases de desenvolvimento deste trabalho.

Ao Programa de Pós Graduação em Zootecnia da Faculdade de Medicina Veterinária e Zootecnia - UNESP/Botucatu, pela oportunidade de realização deste curso.

Aos Professores do Departamento de Melhoramento e Nutrição Animal da FMVZ, Botucatu - SP, pelo apoio durante a realização do curso.

À Coordenação de Aperfeiçoamento de Pessoal de Nível Superior (CAPES), pela concessão da bolsa de estudos.

Aos funcionários do Laboratório de Nutrição de Aves Sr. Arlindo e Tiago pela dedicação, amizade e auxílios prestados.

Aos funcionários do Departamento de Melhoramento e Nutrição Animal da FMVZ Carlão, Magali e Silene.

Aos funcionários da Seção de Pós-Graduação, Seila e Carlos pelos auxílios prestados.

Ao Professor Carlos Ducatti, aos funcionários e amigos do Centro de isótopos Estáveis Ambientais: Cibele, Evandro e Silvia, pelo auxílio nas análises isotópicas.

Às amigas Juliana Célia Denadai e Rosana Gottmann, pela amizade, imensa paciência e pela contribuição nas idéias e discussão do trabalho.

Aos meus amigos Luciene, Vanessa, Kelen, Ana Cristina, Celina, Érica, Fabyola, Mariana, Carolina, Thaila, Marcos Paulo e Vitor por contribuir de alguma forma, seja na execução do experimento ou nas horas de descontração.

Ao meu namorado, Rafael, por toda paciência, companheirismo e amor.

A minha cunhada Daniela por ter me dado dois sobrinhos maravilhosos.

Ao meu cunhado Wenzel pela amizade e cuidar da minha irmã.

E à todos aqueles que, de alguma forma, contribuíram para realização deste trabalho 


\section{SUMÁRIO}

Página

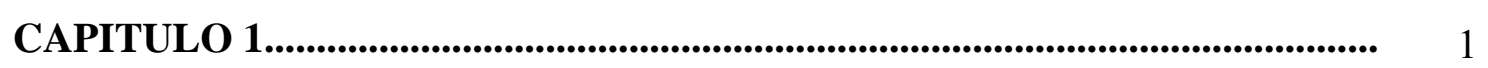

CONSIDERAÇÕES INICIAIS........................................................................... 2

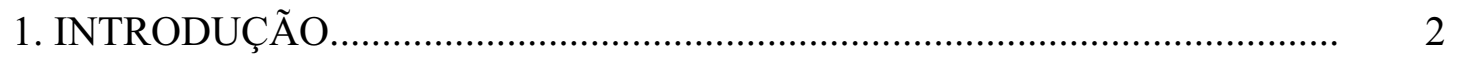

2. RASTREABILIDADE ................................................................................

3. ISÓTOPOS ESTÁVEIS............................................................................. 5

4. TECIDOS ANALISADOS ……………………………………………........

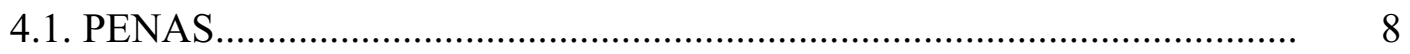

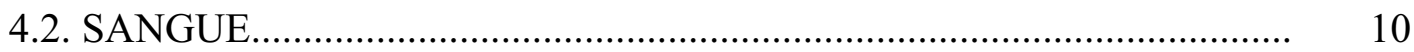

REFERÊNCIAS BIBLIOGRÁFICAS..................................................................... 13

CAPÍTULO 2.......................................................................................... 23

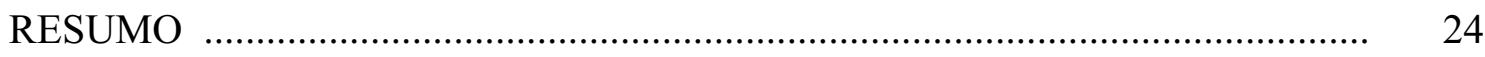

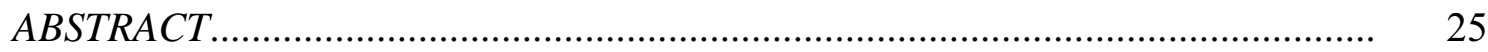

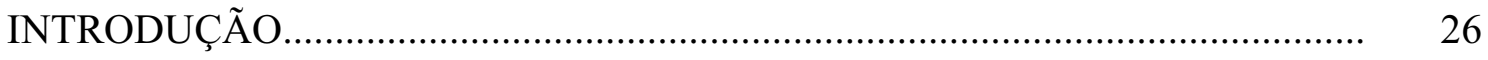

MATERIAL E MÉTODOS............................................................................. 28

RESULTADOS E DISCUSSÃO_........................................................................ 32

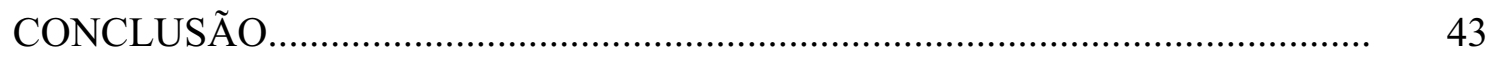

REFERÊNCIAS BIBLIOGRÁFICAS.................................................................... 44

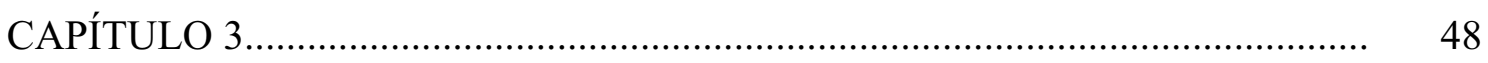

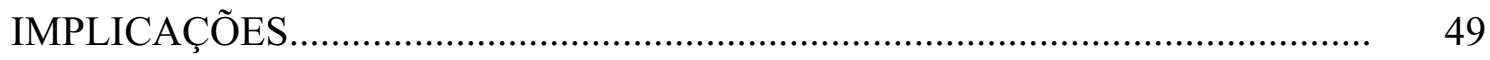




\section{LISTA DE TABELAS}

Página

Tabela 1 - Composição percentual dos ingredientes, teores nutricionais calculados para as rações experimentais 1 a 21 dias de idade

Tabela 2 - Composição percentual dos ingredientes, teores nutricionais calculados para as rações experimentais 22 a 42 dias de idade

Tabela 3 - Valores Isotópicos médios de $\delta^{13} \mathrm{C}$ e $\delta^{15} \mathrm{~N}$ da ração, e seus desviospadrão, da ração de frangos de corte criados até os 42 dias de idade.

Tabela 4 - Valores médios de $\delta^{13} \mathrm{C}$ e $\delta^{15} \mathrm{~N}$, e seus desvios-padrão, das penas de frangos de corte criados até os 42 dias de idade.

Tabela 5 - Valores médios de $\delta^{13} \mathrm{C}$ e $\delta^{15} \mathrm{~N}$, e seus desvios-padrão, do sangue de frangos de corte criados até os 42 dias de idade. 


\section{LISTA DE FIGURAS}

Página

\section{CAPÍTULO 1}

Figura 1 - Principais partes de uma pena de contorno.

\section{CAPÍTULO 2}

Figura 1- Coleta de penas.

Figura 2- Regiões de confiança formadas pela diferença entre os valores isotópicos de $\delta^{13} \mathrm{C}$ e $\delta^{15} \mathrm{~N}$ de Penas e Sangue de frangos de corte aos 7 dias de idade de cada tratamento quando comparados ao tratamento controle.

Figura 3 - Regiões de confiança formadas pela diferença entre os valores isotópicos de $\delta^{13} \mathrm{C}$ e $\delta^{15} \mathrm{~N}$ de Penas e Sangue de frangos de corte aos 14 dias de idade de cada tratamento quando comparados ao tratamento controle.

Figura 4 - Regiões de confiança formadas pela diferença entre os valores isotópicos de $\delta^{13} \mathrm{C}$ e $\delta^{15} \mathrm{~N}$ de Penas e Sangue de frangos de corte aos 21 dias de idade de cada tratamento quando comparados ao tratamento controle

Figura 5 - Regiões de confiança formadas pela diferença entre os valores isotópicos de $\delta^{13} \mathrm{C}$ e $\delta^{15} \mathrm{~N}$ de Penas e Sangue de frangos de corte aos 28 dias de idade de cada tratamento quando comparados ao tratamento controle

Figura 6 -Regiões de confiança formadas pela diferença entre os valores isotópicos de $\delta^{13} \mathrm{C}$ e $\delta^{15} \mathrm{~N}$ de Penas e Sangue de frangos de corte aos 35 dias de idade de cada tratamento quando comparados ao tratamento controle

Figura 7 -Regiões de confiança formadas pela diferença entre os valores isotópicos de $\delta^{13} \mathrm{C}$ e $\delta^{15} \mathrm{~N}$ de Penas e Sangue de frangos de corte aos 42 dias de idade de cada tratamento quando comparados ao tratamento controle. 
CAPITULO 1 


\section{CONSIDERAÇÕES INICIAS}

\section{INTRODUÇÃO}

A cadeia produtiva de frangos de corte assegura ao país uma posição de destaque no cenário mundial de produtores de carne de frango. Segundo a Associação Brasileira dos Produtores e Exportadores de Frangos (ABEF, 2008), o Brasil é o terceiro maior produtor e o maior exportador de carne de frango na classificação mundial.

A demanda por alimentos de produtos de origem animal vem crescendo de maneira cada vez mais rápida. Para atender essa demanda, os alimentos são produzidos e comercializados em larga escala e em condições extremamente intensivas. Esse fato pode acarretar conseqüências indesejáveis e muitas vezes prejudiciais aos consumidores. Intoxicações, infecções e mortes decorrentes de contaminações não intencionais são cada vez mais freqüentes. Episódios como salmonelose em ovos na Grã-Betanha, a contaminação com dioxina em frangos e suínos na Bélgica, surtos de febre aftosa em vários países, a encefalopatia espongiforme bovina (EEB), conhecida como doença da vaca louca na Inglaterra e Canadá e recentemente a Influenza Aviária na Ásia, contribuíram para o aumento da preocupação dos consumidores em relação à qualidade dos alimentos comercializados (Felício, 2001).

Para atender aos atuais padrões de exigência do consumidor, cada vez mais preocupado em relação à rastreabilidade de alimentos de origem animal, as empresas estão adotando sistemas para melhorar o controle de qualidade, tanto de seus produtos, quanto no impacto ao meio ambiente e na sociedade. Deste modo, a União Européia editou normas de utilização sanitárias para utilização de subprodutos de origem animal em rações de animais da mesma espécie, restringindo o uso destes subprodutos (Ceruti, 2007).

A técnica dos isótopos estáveis apresenta potencial de aplicação prática para a detecção destes subprodutos na alimentação animal, por meio da análise dos tecidos da ave, como músculos, vísceras, ossos e ovos, sendo que como o sangue e as penas, há poucos trabalhos conduzidos. Uma das vantagens de se trabalhar com estes tecidos é que se podem colher amostras nas diversas etapas de criação, sem necessidade de sacrifício das aves. 


\section{RASTREABILIDADE}

A rastreabilidade é um sistema que permite traçar o histórico, a identificação, a localização de um produto por meio de informações previamente registradas. Com o uso do mecanismo da rastreabilidade, pode-se levantar a origem do produto desde a produção da matéria-prima, dos insumos, até chegar ao consumidor final, podendo ter sido processado ou não (Cima et al., 2006).

Os selos de qualidade e certificação de origem, como afirmou Spers (2000), vêm sendo desenvolvidos com o objetivo de conquistar a confiança do mercado consumidor, que vem demonstrando maior preocupação com relação aos atributos de qualidade nos alimentos.

As informações necessárias contidas no rótulo do produto podem oferecer informação ao consumidor final para escolha de um determinado produto, além de assegurar suas características de qualidade especificadas. Portanto, isso deve ser tratado com grande importância por produtores e autoridades competentes, pois cada vez mais, os consumidores exigem transparência dos alimentos que compram, querendo saber como e onde os animais são criados (Cima et al., 2006).

Um sistema de certificação assegura que o produto está enquadrado em especificações predeterminadas, pois é a certificação que define os atributos desse produto, processo ou serviço e garante que eles estejam inseridos em normas predefinidas. Nesse sentido, a certificação envolve normas, tanto na esfera pública quanto na privada, nacional e internacional (ambiente institucional), e um órgão certificador com poder de monitorar e excluir aqueles que não seguirem tais normas ambiente organizacional (Nassar, 2003).

A maioria dos sistemas de rastreabilidade nas cadeias agroalimentares do Brasil estão no começo de implantação e sua evolução se dá de forma lenta. Em janeiro de 2002, o Ministério da Agricultura, Pecuária e Abastecimento por meio da Instrução Normativa $\mathrm{n}^{\mathrm{o}}$ 1, instituiu o Sistema Brasileiro de Identificação e Certificação de Origem Bovina e Bubalina - SISBOV. Na avicultura a pioneira foi à empresa Perdigão, que implantou o sistema de rastreabilidade em 1997. No entanto, apesar do alto grau de organização e coordenação da cadeia produtiva da avicultura de corte no País, o processo de rastreabilidade está ainda na fase inicial (Cima et al., 2006), não dispondo 
de sistema de identificação oficial como a pecuária de corte, mas já utiliza diversas ferramentas de gestão e controle de qualidade em sua cadeia, como o APPCC (Análise de Perigo em Pontos Críticos de Controle) ou o BPF (Boas Práticas de Fabricação), além de atuar no sentido de definir normas para outros pontos da cadeia produtiva (Cerutti, 2002).

Para que a rastreabilidade avícola seja bem-sucedida, além dessas ferramentas de gestão e controle de qualidade, é necessária a criação de análise de contra prova que auxiliasse atestar a veracidade das informações constantes no histórico alimentar de lotes de produtos diferenciados (como por exemplo, carne de frango e ovos provenientes de aves alimentadas com dieta estritamente vegetal) e que pudesse monitorar o processo de rastreabilidade e fornecer laudos técnicos para as auditorias, como instrumento de confiabilidade (Oliveira, 2005).

A técnica de isótopos estáveis tem sido usada com sucesso para testar a autenticidade e qualidade de vários produtos tais como sucos de frutas (Bricout \& Koziet, 1987; Koziet et al., 1993), vinhos (Martin et al., 1988), méis (Brookes et al., 1991; Reniero et al., 1997; White et al., 1998), produtos lácteos (Rossmann et al., 2000; Manca et al., 2001), óleos vegetais (Kelly et al., 1997) e, a caracterização e diferenciação do regime dietético de suínos Ibéricos, possibilitando a classificação dos animais de acordo com o tipo de alimentação recebida durante o período de engorda (González-Martín et al., 1999; González-Martín et al., 2001). Em associação com a razão isotópica do elemento químico do nitrogênio $\left({ }^{15} \mathrm{~N} /{ }^{14} \mathrm{~N}\right)$, permitiu a certificação de origem geográfica e tipos de alimentação de ovinos e bovinos (Piasentier et al., 2003; Schmidt et al., 2005).

De acordo com Carrijo (2003), a técnica dos isótopos estáveis de carbono e nitrogênio pode ser utilizada como ferramenta para rastrear a inclusão de subprodutos de origem animal em dietas de frangos de corte por meio da análise da razão isotópica do músculo peitoral (Pectoralis major). Além disso, o autor sugere que o aprimoramento dessa técnica pode possibilitar a certificação de que frangos destinados ao mercado externo que foram alimentados exclusivamente com ingredientes de origem vegetal.

No Centro de Isótopos Estáveis Ambientais da UNESP, Campus de Botucatu, fundamentada nesta técnica, surgiu à linha de pesquisa que visa detectar da inclusão de 
farinhas de origem animal na alimentação de aves de postura (Carrijo et al., 2000; Denadai et al., 2006; Denadai et al., 2008), frangos de corte (Cruz et al., 2004; Oliveira, 2005; Carrijo et al., 2006; Gottmann, 2008) e codornas (Móri et al., 2007; Sernagiotto, 2009). Esses pesquisadores confirmaram que esta técnica é eficaz na detecção de farinhas de origem animal em diversos tecidos de aves.

A escolha de se trabalhar com sangue e penas, permite colher amostras nas diversas etapas de criação, podendo compor estratégias de amostragem sem necessidade de sacrifício das aves e de fácil aplicação, servindo como ferramenta de apoio às auditorias e certificação de criações de frangos isentas de proteínas de origem animal na dieta.

\section{ISÓTOPOS ESTÁVEIS}

O termo isótopo vem do grego: ISO (mesmo ou igual) e TOPOS (lugar), referindose ao fato de ocuparem o mesmo lugar na tabela periódica. A expressão estável significa dizer que não emitem radiação.

Os isótopos são átomos do mesmo elemento químico, mas que diferem em número de nêutrons e número de massas. O diferente número de massa dos isótopos possibilita a sua identificação, através da espectrometria de massa, e sua utilização em estudos geológicos e ambientais. Ou seja, é possível quantificar os diferentes isótopos de um mesmo elemento. Os isótopos podem ter núcleos instáveis ou estáveis. Os isótopos de núcleos instáveis, também chamados de radioativos, sofrem desintegração espontânea, por emissão de partículas nucleares ou radiação eletromagnética, e geram os isótopos radiogênicos. Já os isótopos de núcleos estáveis não se desintegram por nenhum processo conhecido e correspondem a aproximadamente 270 nuclídeos. Os isótopos ambientais são isótopos de elementos em abundância e de ocorrência natural no nosso planeta, como o H, C, N, O e S. Eles são os principais elementos dos ciclos hidrológico, geológico e biológico. A mensuração dos isótopos ambientais vem crescendo, conforme se aprimora a rotina de laboratórios e equipamentos (Clark \& Fritz, 1997).

Os isótopos do carbono $(\mathrm{C})$, hidrogênio $(\mathrm{H})$, oxigênio $(\mathrm{O})$, nitrogênio $(\mathrm{N})$ ocorrem naturalmente na biosfera. Cada elemento apresenta um isótopo estável leve dominante: 
carbono-12 $\left({ }^{12} \mathrm{C}\right)$, hidrogênio-1 $\left({ }^{1} \mathrm{H}\right)$, oxigênio-16 $\left({ }^{16} \mathrm{O}\right)$ e nitrogênio-14 $\left({ }^{14} \mathrm{~N}\right)$ e um ou dois isótopos estáveis pesados: carbono-13 $\left({ }^{13} \mathrm{C}\right)$, hidrogênio-2 $\left({ }^{2} \mathrm{H}\right)$, oxigênio-17 $\left({ }^{17} \mathrm{O}\right)$, oxigênio-18 $\left({ }^{18} \mathrm{O}\right)$ e nitrogênio-15 $\left({ }^{15} \mathrm{~N}\right)$, com abundância ou concentração natural expressa em átomos \% (Ducatti, 2004).

A abundância natural para os isótopos estáveis de carbono $\left({ }^{12} \mathrm{C}\right.$ e $\left.{ }^{13} \mathrm{C}\right)$, e de aproximadamente 98,89 e 1,11 átomos \%, respectivamente (Kennedy \& Krouse, 1990). E nitrogênio ( ${ }^{14} \mathrm{~N}$ e $\left.{ }^{15} \mathrm{~N}\right)$ são 99,63 e 0,37 átomos \%, respectivamente (Ducatti, 2004). A medida da relação entre isótopos é realizada pelo espectrômetro de massas, que mede a concentração dos diferentes isótopos do elemento, admitido no sistema sob a forma gasosa $\left(\mathrm{H}_{2}, \mathrm{CO}_{2}, \mathrm{~N}_{2}\right.$ e $\left.\mathrm{SO}_{2}\right)$.

A razão entre os isótopos estáveis, mensurados por espectrometria de massa de baixa resolução, com leitura em delta $(\delta)$ é obtida pela expressão:

\section{$\delta X($ amostra, padrão $)=[($ Ramostra - Rpadrão $) /$ Rpadrão $] \times 1000$}

onde:

$\delta \mathrm{X}=$ enriquecimento do isótopo mais pesado do elemento químico $\mathrm{X}(\mathrm{C}$ ou $\mathrm{N}) \mathrm{da}$ amostra em relação ao respectivo padrão internacional.

$\mathrm{R}=$ representa a razão isotópica entre o isótopo menos e o mais abundante, ${ }^{13} \mathrm{C} /{ }^{12} \mathrm{C}$ e ${ }^{15} \mathrm{~N} /{ }^{14} \mathrm{~N}$.

Os valores do delta do carbono-13 são expressos em um padrão internacional Peedee Belemnite (PDB). Segundo Friedman \& O'Neil (1977), o padrão PDB é aceito universalmente na comparação das composições isotópicas do carbono. Trata-se de um carbonato sólido de Belemnitela americana, da formação Peedee da Carolina do Sul, Estados Unidos, empregado inicialmente como padrão por Craig (1957). Para os isótopos estáveis do nitrogênio, o padrão internacional é o nitrogênio do ar atmosférico, o qual é considerado uma mistura isotópica homogênea na superfície terrestre. Os valores isotópicos de nitrogênio-15 também são expressos, na notação delta per mil $\left(\delta^{15} \mathrm{~N}\right)$ da razão isotópica ${ }^{15} \mathrm{~N} /{ }^{14} \mathrm{~N}$ do produto em relação ao padrão internacional.

As plantas, na sua maioria, podem ser classificadas em dois grupos principais, de acordo com a via fotossintética de fixação do $\mathrm{CO}_{2}$ : ciclo fotossintético $\mathrm{C}_{3}$ e ciclo fotossintético $\mathrm{C}_{4}$. Nestas plantas o primeiro composto orgânico a ser formado é um 
ácido carboxílico, que nas $\mathrm{C}_{3}$ possui três átomos de carbono e nas $\mathrm{C}_{4}$ possui quatro átomos de carbono.

A via fotossintética $\mathrm{C}_{3}$ inclui a maioria das árvores, arbustos, soja, arroz, trigo, cevada, algodão entre outros, e a via fotossintética $\mathrm{C}_{4}$ é encontrada no milho, cana de açúcar, sorgo, e outras forrageiras de origem tropical ou subtropical.

$\mathrm{O} \mathrm{CO}_{2}$ atmosférico que possui valor de $\delta^{13} \mathrm{C}$ de aproximadamente -7,7\%o (Kennedy \& Krouse, 1990), é a fonte primária de carbono para as plantas terrestres. Este carbono sofre discriminação isotópica ao longo do processo de fotossíntese, ocorrendo diminuição da concentração de ${ }^{13} \mathrm{C}$ e aumento da concentração de ${ }^{12} \mathrm{C}$. Durante a assimilação fotossintética, as plantas do ciclo fotossintético $\mathrm{C}_{3}$ fixam o $\mathrm{CO}_{2}$ atmosférico através do ciclo Calvin-Benson e apresentam valores de $\delta^{13} \mathrm{C}$ entre -22 e $34 \%$ (valor modal $=-26,7 \%$ ), enquanto as plantas do ciclo fotossintético $\mathrm{C}_{4}$ fixam o $\mathrm{CO}_{2}$ atmosférico através do ciclo Hatch-Slack e apresentam valores de $\delta^{13} \mathrm{C}$ entre -9 e $16 \%$ (valor modal $=-12,6 \%$ ). O sinal negativo indica que a planta ou seu subproduto apresenta menor concentração de ${ }^{13} \mathrm{C}$ que o padrão internacional. Portanto, as plantas $\mathrm{C}_{3}$ e $\mathrm{C}_{4}$ possuem assinaturas isotópicas diferentes, devido ao fracionamento que ocorre durante a fixação fotossintética do carbono (Smith \& Epstein, 1971; O’Leary, 1981; Kennedy \& Krouse, 1990; Vogel, 1993).

Considerando-se a existência da diferença isotópica da ordem de 14\%o mais rico em ${ }^{13} \mathrm{C}$ nas plantas do ciclo fotossintético $\mathrm{C}_{4}$, em relação às do ciclo fotossintético $\mathrm{C}_{3}$, torna-se possível a utilização destas plantas e seus subprodutos como marcadores em animais, sem a necessidade de sintetizar compostos especificamente marcados (Ducatti, 2004).

Diferentemente do carbono, a razão isotópica ${ }^{15} \mathrm{~N} /{ }^{14} \mathrm{~N}$ nas plantas não depende do ciclo fotossintético realizado. Mesmo a atmosfera sendo abundante em $\mathrm{N}_{2}$, somente as plantas que possuem bactérias fixadoras de nitrogênio conseguem fixá-lo do ar. As demais plantas o fixam através da incorporação de compostos nitrogenados do solo. Quando o nitrogênio é absorvido do ar atmosférico pelas bactérias fixadoras ou pelo uso de fertilizantes industriais, o valor do $\delta^{15} \mathrm{~N}$ no solo é baixo, em torno de $0 \%$. Se absorvido da matéria orgânica decomposta, o valor do $\delta^{15} \mathrm{~N}$ é mais significativo, ao redor de 5\%. Valores negativos de $\delta^{15} \mathrm{~N}$ são observados em solos com baixa porcentagem de matéria orgânica, em particular solos secos e arenosos. Quando for 
adicionado esterco como fertilizante natural, a taxa de fracionamento é alta, com valores de $\delta^{15} \mathrm{~N}$ em torno de $10 \%$ (Shibuya et al., 2006).

Uma vez que os tecidos corporais refletem o sinal isotópico das dietas que os animais consomem, as farinhas de origem animal são reflexo da dieta do animal que a deu origem, variando por volta de $2 \%$ para o $\delta^{13} \mathrm{C}$ (Deniro \& Esptein, 1978) e em torno de $3 \%$ (2-5\%), para o $\delta^{15} \mathrm{~N}$, devido o nitrogênio do organismo animal sofrer enriquecimento em cada elevação do nível trófico (Deniro \& Esptein, 1981).

A análise da variação natural da abundância dos isótopos estáveis representa uma ferramenta poderosa para as pesquisas em geologia e arqueologia, possibilitando a reconstrução da dieta prévia de animais (Van der Merve, 1982; DeNiro, 1987). Nas últimas décadas os isótopos estáveis têm sido aplicados de forma crescente e contínua em pesquisas agrícolas, ecológicas e fisiológicas e apresentam-se como alternativa promissora para estudar processos relacionados à digestão, absorção e metabolismo de nutrientes em humanos e animais, assim como, para identificar a procedência e a qualidade de produtos de origem animal e vegetal (Gannes et al., 1998).

\section{TECIDOS ANALISADOS}

\subsection{PENAS}

As penas constituem um importante componente corporal das aves, correspondendo a aproximadamente 4 a $8 \%$ do peso vivo, com variações em função do sexo e idade (North \& Bell, 1993). As penas contêm aproximadamente 7,9\% de umidade, $89-97 \%$ de proteína (principalmente queratina) e 1,3\% de lipídios (declina com a idade da ave).

O desenvolvimento das penas, como outros sistemas e órgãos, envolvem uma série de complexos processos morfológicos e fisiológicos, importante para estabelecer o padrão e a forma final das penas. Cada uma das penas possui um único folículo e uma papila localizada na sua base, dispostos de um modo definido (em fileiras ou linhas) pelo corpo do animal. Todas as gerações de penas crescem a partir das papilas formadas durante a fase pré-natal, ou seja, os números de penas correspondem ao número de folículos encontrados no embrião (Macari et al., 1994). 
Os folículos podem ser induzidos a produzir uma nova pena em quase todo o tempo, se uma pena é arrancada do folículo. A seqüência de mudas é ordenada, provavelmente sob a ação dos hormônios liberados pelos folículos adjacentes (Leeson $\&$ Walsh, 2004). Na maioria das aves, as penas da asa são as primeiras a mudar, seguido pelas penas do corpo e por último a cabeça e pescoço. Em condições naturais, a muda nos machos ocorre antes das fêmeas (Spearman, 1971). Durante a muda, as penas velhas são simplesmente empurradas para fora pela pena nova. As penas emergentes estão fisicamente ligadas à pena antiga, que emerge da bainha exterior, a ligação é interrompida e as penas velhas caem (Leeson \& Walsh, 2004).

Um importante aspecto a ser observado no desenvolvimento das penas é o fato dessas não crescerem continuamente. $\mathrm{O}$ rápido desenvolvimento de penas ocorre entre 3 e 6 semanas de idade, embora o período de máximo crescimento das penas possa ser influenciado pela genética, sexo, nutrição e estação do ano (Leeson \& Walsh, 2004). Yalcin et al. (1997) mostraram que frangos de corte com 4 a 7 semanas de idade têm mais penas no verão (média temperatura de $27^{\circ} \mathrm{C}$ ) do que no inverno (média de temperatura de $20^{\circ} \mathrm{C}$ ). A diferença foi de $0,5 \%$ do peso corporal em favor do verão. A exata razão para esta diferença não está clara, mas pode estar relacionada com o fato de que o crescimento das penas pode ser menos influenciado pelo ambiente quente que o crescimento do frango. O comprimento das penas aumenta naturalmente quando as aves envelhecem. McDougald \& Keshavarz (1984) mostraram um aumento quase linear no comprimento das penas de contorno e primárias em frangos de corte com o aumento da idade de abate.

A adequação nutricional da dieta parece ser o principal fator a influenciar tanto a estrutura e o crescimento das penas de frango de corte (Wyatt et al., 1975). Uma vez que $89-97 \%$ das penas é proteína (Fisher et al., 1981), os aminoácidos desempenham um papel crítico no desenvolvimento de penas. A cistina e a metionina são os principais aminoácidos envolvidos na síntese de queratina das penas (Wheeler \& Latshaw, 1981). A cistina é o principal componente da queratina, enquanto que a metionina está envolvida através da sua conversão para a cistina (Champe \& Maurice, 1984). Além de seu papel na síntese de pena, metionina e cistina, também são necessárias para a manutenção geral do crescimento (Wheeler \& Latshaw, 1981). 
As penas são, provavelmente, uma das mais complexas estruturas, existindo vários tipos de penas, cada uma com função e característica estruturais específicas que contribuem com sua finalidade funcional. Essas incluem a penugem, que existe por ocasião do nascimento; por volta do décimo quarto dia, caem e surgem as penas juvenis, que começam a crescer inicialmente nas asas e, posteriormente, as penas adultas que substituem as penas juvenis (Spearman, 1971). Encontram-se três tipos básicos de penas: semipluma, na qual a barba é fofa e a ráquis curta, e se localizam às margens das penas de contorno, próximas do corpo; filopluma, que é rudimentar e distribuída em todos os tratos de penas do corpo inclusive nas penas da cabeça; e as penas de contorno, são as penas externas que cobrem todo o corpo, formando uma camada isolamento térmico (Macari et al., 1994).

Conforme a Figura 1 as principais partes estruturais de uma pena são: cálamo, ráquis, eixo, barbas, bárbulas e barbículas, onde o eixo é composto por dois segmentos, o cálamo e ráquis. O cálamo é a base curta e tubular implantada no folículo das penas, onde existe uma abertura em sua base inferior, através da qual a pena recebe os elementos para o seu crescimento. A ráquis é a porção longa e sólida do eixo acima da pele. De cada lado do eixo existem finas ramificações que são conhecidas como barbas que também possui ramificações muito pequenas chamadas de bárbulas que, por sua vez, têm ramificações muito pequenas chamadas de barbículas (Macari et al., 1994).

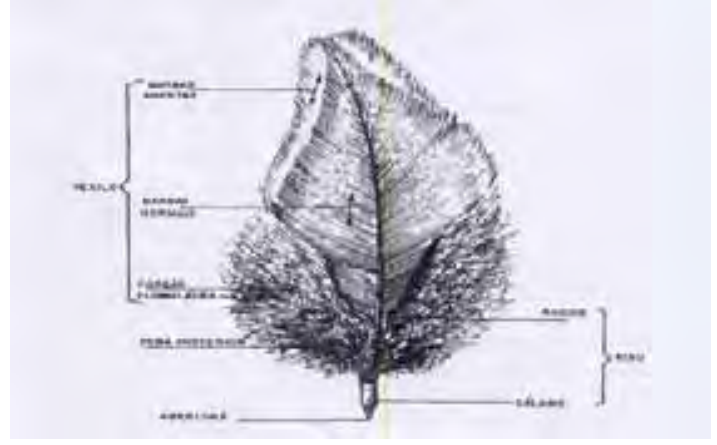

FIGURA 1. Principais partes de uma pena de contorno (Macari et al., 1994).

\subsection{SANGUE}

O sangue representa ao redor de $7 \%$ do peso vivo do frango de corte. O sangue é composto por duas partes, sendo uma composta de células e outra fluida. Na parte celular encontram-se os eritrócitos (hemácias), leucócitos (glóbulos brancos) e 
trombócitos. O número de leucócitos varia entre 2.000 até 3.000 células/ $\mu \mathrm{L}$. No entanto esse número pode variar em função de sexo, idade, condições de estresse e doenças. $\mathrm{Na}$ hemácia encontra-se a hemoglobina que, devida a sua alta afinidade pelo oxigênio e gás carbônico, é responsável pelo transporte desses gases no sangue. As hemácias são produzidas nos órgãos hematopoiéticos (medula óssea), sendo sua vida média ao redor de 28 a 35 dias (Macari et al., 1994).

O sangue das aves não contém plaquetas; os trombócitos é que desempenham o papel delas durante os mecanismos de coagulação do sangue. A coagulação é um mecanismo importante, pois evita a perda de sangue por ocasião de hemorragia. Ela implica na formação do coágulo que nada mais é do que a transformação de uma proteína solúvel, o fibrinogênio, em proteína insolúvel, a fibrina. (Macari et al., 1994).

Depois da remoção do fibrinogênio e da fibrina, o fluido remanescente é denominado soro (Banks, 1992). A fração fluída do sangue é denominada de plasma, com sais e proteínas dissolvidas. O plasma forma de 55 a 70 volumes por cento do sangue total. Além de água, seu constituinte maior, contêm, em solução,gases e outros componentes minerais bem como considerável variedade de constituintes orgânicos nitrogenados (não protéicos e protéicos) e não nitrogenados. Enzimas, hormônios, vitaminas e seus derivados coenzimátiocos, metabólitos variados. Muitas das características atribuídas ao plasma são funções dos seus componentes protéicos, os quais auxiliam na manutenção da pressão osmótica intravascular (pressão coloidosmótica), no transporte de vários constituintes plasmáticos (hormônios, produtos residuais), no mecanismo de coagulação e na proteção do corpo pelos anticorpos humorais imunoglobulinas. (Lehninger et al., 1995).

Penas e sangue de aves são tecidos cada vez mais escolhidos para estudos de isótopos estáveis por ecologistas (Bearhop et al., 2002). Mizutani et al. (1992) ao estudarem a influência da dieta na distribuição dos isótopos de carbono em penas de 11 espécies de aves, concluíram que as penas também refletem a dieta das aves através da análise da taxa de turnover, da composição bioquímica e da fonte orgânica do tecido.

Pesquisadores têm mostrado que a taxa de turnover do isótopo de carbono dentro de um tecido está relacionado com a taxa metabólica (Tieszen et al., 1983; Hobson \& Clark, 1992a). Ambos os estudos apresentam taxa de turnover mais rápida nos tecidos com maiores taxas metabólicas, tais como fígado e sangue, que nos tecidos com taxas 
metabólicas mais baixas, tais como colágeno ósseo. Para aves, a composição isotópica das penas reflete a dieta durante o período de crescimento (Mizutani et al., 1991, 1992; Hobson \& Clark, 1992b; Thompson et al., 1998).

Para Pearson et al. (2003), a taxa de turnover é importante para determinar como a assinatura isotópica da dieta de um animal é incorporada em seus tecidos. Em seus estudos, estes autores indicaram que o plasma sanguíneo fornece informações de curto prazo (cerca de 1-4 dias), enquanto o sangue total fornece mais informações (cerca de 812 dias) porque suas células têm maior longevidade do que os constituintes do plasma, tendo um ritmo mais lento na taxa de turnover; e, as penas refletem a dieta durante o seu período de crescimento.

Voigt et al. (2003) em estudo com duas espécies de morcego (Leptonycteris curasoae e Glossophaga soricina) coletou três tipos de tecidos: pêlos, membrana da asa e sangue. O sangue foi coletado como padrão (tecido alvo), que mostra a mais alta taxa de turnover; pequenos pedaços de membrana da asa, para apresentar uma taxa de turnover intermediária em relação ao sangue e pêlos. Os pêlos apresentam baixa taxa de turnover. Em roedores as taxas de turnover dos isótopos de carbono foram elevadas na gordura e no fígado, intermediárias nos músculos e baixas no cérebro e pêlos (Tieszen et al., 1983). Os isótopos estáveis podem fornecer informações da dieta na gordura e no fígado em curto prazo, nos músculos médio prazo e no cérebro e pêlos a longo prazo

Trabalhar com sangue e penas possibilita colher amostras nas diversas etapas de criação sem necessidade de sacrifício das aves. Por serem tecidos com metabolismo diferente, estes refletem de maneira distinta o sinal isotópico da dieta em diferentes períodos de criação, permitindo identificar a presença de farinha de vísceras na alimentação dos frangos de corte.

O Capitulo 2 intitulado "ISÓTOPOS ESTÁVEIS NA RASTREABILIDADE DE FARINHA DE VÍSCERAS DE AVES NA ALIMENTAÇÃO DE FRANGOS DE CORTE" encontra-se redigido de acordo com as normas editoriais da Revista $P A B$ Pesquisa Agropecuária Brasileira. O presente trabalho teve por objetivo analisar sangue e penas, para detectar a presença de farinha de vísceras de frango na alimentação de frangos de corte através da análise dos isótopos estáveis de carbono $\left({ }^{13} \mathrm{C} /{ }^{12} \mathrm{C}\right) \mathrm{e}$ nitrogênio $\left({ }^{15} \mathrm{~N} /{ }^{14} \mathrm{~N}\right)$ por espectrometria de massas. 


\title{
REFERÊNCIAS BIBLIOGRÁFICAS
}

\begin{abstract}
ABEF -Associação brasileira de produtores e exportadores de frangos. Números finais em 2008. Disponível em www.abef.com.br Acesso em 16 abr.2009.
\end{abstract}

BANKS, W.J. Histologia veterinária aplicada. São Paulo: Manole, 1992. 629p.

BEARHOP, S.M.; WALDRON, S.; VOTIER, S.C.; FURNESS, R.W. Factors that influence assimilation rates and fractionation of nitrogen and carbon stable isotopes in avian blood and feathers. Physiological and Biochemical Zoology, University of Chicago, v.75, p.451-458, 2002.

BRICOUT, J.; KOZIET, J. Control of the authenticity of orange juice by isotopic analysis. Journal of Agricultural Food Chemistry, v.35, p.758-760, 1987.

BROOKES, S.T.; BARRIE, A.; DAVIES, J.E. A rapid ${ }^{13} \mathrm{C} /{ }^{12} \mathrm{C}$ test for determination of corn-syrups in honey. Journal of the Association of Official Analytical Chemists, v.74, p.627-629, 1991.

CARRIJO, A.S.; PEZZATO, A.C.; DUCATTI, C. Avaliação do metabolismo nutricional em poedeiras pela técnica dos isótopos estáveis do carbono $\left({ }^{13} \mathrm{C} /{ }^{12} \mathrm{C}\right)$. Revista Brasileira de Ciência Avícola, v.2, n.3, p. 209-218, 2000.

CARRIJO, A.S. Técnica dos isótopos estáveis do carbono $\left({ }^{13} \mathrm{C} /{ }^{12} \mathrm{C}\right)$ e nitrogênio $\left({ }^{15} \mathrm{~N} /{ }^{14} \mathrm{~N}\right)$ em frangos de corte. 2003. Tese (Doutorado em Zootecnia) - Faculdade de Medicina Veterinária e Zootecnia, Universidade Estadual Paulista, Botucatu, 92p. 2003. 
CARRIJO, A.S.; PEZZATO, A.C.; DUCATTI, C.; SARTORI, J.R.; TRINCA, L.; SILVA, E.T. Traceability of Bovine Meat and Bone Meal in Poultry by Stable Isotope Analysis. Revista Brasileira de Ciência Avícola, Campinas, v.8, n.1, p.37-42, 2006.

CERUTI, F.C. Rastreabilidade de grãos: conceito, desenvolvimento de software e estudos de casos de manejo de insetos no armazenamento. Dissertação (Doutorado em Ciências Biológicas-Área de Concentração em Entomologia). Universidade Federal do Paraná, Curitiba, 2007.

CERUTTI, M. Aplicação de um programa de rastreabilidade na cadeia de frangos de corte. In: SIMPÓSIO SOBRE MANEJO DE AVES E SUÍNOS E TECNOLOGIA DA PRODUÇÃO DE RAÇÕES. Anais... Campinas: Colégio Brasileiro de Nutrição Animal, 2002. p. 253-264.

CHAMPE, K.A.; MAURICE, D.V. Plasma sulfa AA in the domestic hen following molt induced by low sodium diet. Nutrition Report International, v.30, p. 965, 1984.

CIMA, E.G; AMORIM, L.S.B.; SHIKIDA, P.F.A. A importância da rastreabilidade para o sistema de segurança alimentar na industria avícola. Revista FAE, Curitiba, v.9, n.1, p.1-12. 2006.

CLARK, I.; FRITZ, P. Environmental isotopes in hydrogeology. Boca Raton: Lewis Publishers, 1997. 328 p. 
CRAIG, H. Isotopic standards for carbon and oxygen and correction factors for massspectrometric analysis of carbon dioxide. Geochimica et Cosmochimica Acta, v.12, p.133-149, 1957.

CRUZ, V.C.; PEZZATO, A.C.; DUCATTI, C.; PINHEIRO, D.F.; SARTORI, J.R.; GONÇALVES, J.C. Tracing metabolic routes of feed ingredients in tissues of broilerchickens using stable isotopes. Poultry Science, v.83, p.1376-1381, 2004.

DENADAI, J.C.; DUCATTI, C.; PEZZATO, A.C. CARRIJO, A.S; CALDARA, F.R.; OLIVEIRA, R.P Studies on carbon-13 turnover in eggs and blood of commercial layers. Revista Brasileira de Ciência Avícola, v. 8, p. 251-256, 2006.

DENADAI, J.C.; DUCATTI, C.; SARTORI, J.R.; PEZZATO, A.C.; MÓRI,C.; GOTTMANN, R.; MITUO, M.A.O; BORDINHON, A.M The traceability of animal meals in layer diets as detected by stable carbon and nitrogen isotope analysis of eggs. Brazilian Journal of Poultry Science, v. 10, p. 189-194, 2008.

DeNIRO, M.J.; EPSTEIN, S. Influence of diet on the distribution of carbon isotopes in animals. Geochimica et Cosmichimica Acta, London, v.42, p.495-506, 1978.

DeNIRO, M.J., EPSTEIN S. Influence of diet on the distribution of nitrogen isotopes in animals. Geochimica et Cosmichimica Acta, v.45, p.341-351, 1981.

DeNIRO, M.J. Stable isotopes and archaeology. American Scientist, v.75, p.182-191, 1987. 
DUCATTI, C.; SALATI, E.; MATSUI, E. Método de análise da razão ${ }^{13} \mathrm{C} /{ }^{12} \mathrm{C}$ e ${ }^{18} \mathrm{O} /{ }^{16} \mathrm{O}$ em carbonatos. Anais da Academia Brasileira de Ciências, v.51, p.275-286, 1979.

DUCATTI, C. Isótopos estáveis ambientais. [apostila]. Instituto de Biociências, Universidade Estadual Paulista, Botucatu, 184 p. 2004.

FELÍCIO, P.E. Rastreabilidade aplicada à carne bovina. In: $\mathbf{3 8}^{\mathbf{a}}$ Reunião da Sociedade Brasileira de Zootecnia - Piracicaba: FEALQ, p.294-301, 2001.

FISHER, M.; LEESON, S.; MORRISON, W.D. Feather growth and composition of broiler chickens. Canadian Journal of Animal Science, v. 61, p. 769-773, 1981.

FRIEDMAN I, O'NEIL JR. Compilation of stable isotope fractionation factors of geochemical interest. In Fleischer M. Editors. Data of Geochemistry $6^{\mathrm{a}}$ ed. United States government printing office, 1977. p. kk1-kk12.

GANNES, L.Z.; DEL-RIO, C.M.; KOCH, P. Natural abundance variations in stable isotopes and their potential uses in animal physiological ecology. Comparative Biochemistry and Physiology, New York, v.119A, n.3, p.725-737, 1998.

GONZÁLEZ-MARTIN I.; GONZÁLEZ-PÉREZ C.; HERNÁNDEZ-MÉNDEZ J.; MARQUÉS-MACIAS E.; SANZ POVEDA F. Use of isotope analysis to characterize meat from Iberian-breed swine. Meat Science, v.52, p.437-441, 1999. 
GONZÁLEZ-MARTIN, I.; GONZÁLEZ-PÉREZ, C.; HERNÁNDEZ-MÉNDEZ, J.; SÁNCHEZ GONZÁLEZ, C. Differentiation of dietary regimen of Iberian swine by means of isotopic analysis of carbon and sulphur in hepatic tissue. Meat Science, v.58, p.25-30, 2001.

GOTTMANN, R.; PEZZATO, A.C.; DUCATTI, C.; DENADAI,J.C.; MITTUO, M.A.O.; MÓRI, C.; SARTORI, J.R. Ratreabilidade de subprodutos de origem animal em dietas com levedura e trigo para frangos. Revista Agropecuária Brasileira-PAB, Brasília, v.43, n.12, p1641-1647, 2008

HOBSON, K.A.; CLARK, R.G. Assessing avian diets using stable isotopes I: turnover of ${ }^{13} \mathrm{C}$ in tissues. The Condor, Los Angeles, v.94, p.181-188, 1992a.

HOBSON, K.A.; CLARK, R.G. Assessing avian diets using stable isotopes II: factors influencing diet-tissue fractionation. The Condor, Los Angeles, v.94, p.189-197, 1992b.

KELLY, S.; PARKER, I.; SHARMAN, M.; DENNIS, J.; GOODALL, I. Assessing the authenticity of single seed vegetable oils using fatty acid stable carbon isotope ratios $\left({ }^{13} \mathrm{C} /{ }^{12} \mathrm{C}\right)$. Food Chemistry, v.59, n.2, p.181-186, 1997.

KENNEDY, B.V.; KROUSE; H.R: Isotope fractionation by plants and animals: implications for nutrition research. Canadian Journal Physiology and Pharmacology. v.68, p.960-972, 1990. 
KOZIET, J.; ROSSMANN, A.; MARTIN, G.J.; ASHURST, P.R. Determination of carbon-13 content of sugars of fruit and vegetable juices. Analytica Chimica Acta, v.271, p.31-38, 1993.

LEESON S.; WALSH T. Feathering in commercial poultry. Factors influencing feather growth and feather loss. World's Poultry Science Journal, v.60, p.52-63, 2004.

LEHNINGER, A.L.; NELSON, D.L.; COX, M.M. Princípios de bioquímica. 2.ed. São Paulo: Sarvier, p.839,1995.

MACARI, M. FURLAN, R.L; GONZALES, E. Fisiologia aviária aplicada a frangos de corte. Jaboticabal: FUNEP, p.313-323, 1994.

MANCA, G.; CAMIN, F.; COLORU, G.; DEL-CARO, A.; DETENTORI, D.; FRANCO, M. A.; VERSINI, G. Characterization of the geographical origin of Pecorino Sardo cheese by casein stable isotope $\left({ }^{13} \mathrm{C} /{ }^{12} \mathrm{C}\right.$ and $\left.{ }^{15} \mathrm{~N} /{ }^{14} \mathrm{~N}\right)$ ratios and free amino acid ratios. Journal of Agricultural Food Chemistry, v.49, p.1404-1409, 2001.

MARTIN, G.J.; GUILLOU, C.; MARTIN, M.L.; CABANIS, M.T.; TEP, X.; AERNY, J. Natural factors of isotope fractionation and the characterization of wines. Journal of Agricultural Food Chemistry, v.36, p.316-322, 1988.

McCDOUGALD, L.R.; KESHAVARZ, K. The effect of polyether inophore anticoccidial drugs on feather growth in genetically slow-feathering broilers. Poultry Science, v.63, p.1322- 1326, 1984. 
MIZUTANI, H.; KABAYA, Y.; WADA, E. Nitrogen and carbon isotope compositions relate linearly in cormorant tissues and its diet. Isotopenpraxis, v.27, p.166-168, 1991.

MIZUTANI, H.; FUKUDA, M.; KABAYA, Y. ${ }^{13} \mathrm{C}$ and ${ }^{15} \mathrm{~N}$ enrichment factors of feathers of 11 species of adult birds. Ecology, v.13, p.1391-1395, 1992.

MÓRI, C.; GARCIA, E.A.; DUCATTI, C.; DENADAI, J.C.; PELICIA, K.; GOTTMANN, R.; MITUO, M.A.O.; BORDINHON, A.M. Traceability of Animal Byproducts in Quail (Coturnix coturnix japonica) Tissues using Carbon $\left({ }^{13} \mathrm{C} /{ }^{12} \mathrm{C}\right)$ and Nitrogen $\left({ }^{15} \mathrm{~N} /{ }^{14} \mathrm{~N}\right)$ Stable Isotopes. Brazilian Journal of Poultry Science, v.9, n. 4, p. 263 - 269, 2007.

NASSAR, A.M. Certificação no agribusiness. In: Gestão da qualidade no agribusiness. São Paulo: Atlas, p.30-46, 2003.

NORTH, M.O.; BELL, B. Commercial Chicken production manual. New York, Chapman Hall, 4ed. 478p, 1993.

O’LEARY, M.H. Carbon isotope fractionation plants. Phytochemistry, v.20, n.4, p.553-567, 1981.

OLIVEIRA, R.P. Rastreabilidade da farinha de vísceras de aves na alimentação de frangos de corte pela técnica dos isótopos estáveis $\left(\delta^{\mathbf{1 3}} \mathbf{C}\right.$ e $\left.\delta^{\mathbf{1 5}} \mathrm{N}\right)$. 2005. $109 \mathrm{f}$ Tese. (Doutorado em Zootecnia) - Faculdade de Medicina Veterinária e Zootecnia, Universidade Estadual Paulista, Botucatu. 
PEARSON, D.F.; LEVEY, D.J.; GREENBERG, C.H, MARTINEZ DEL-RIO, C. Effects of elemental composition on the icorporation of dietary nitrogen and carbon isotopic signatures in an omnivorous songbird. Oecologia, v.135, p.516-523, 2003.

PIASENTIER, E.; VALUSSO, R.; CAMIN, F.; VERSINI, G. Stable isotope ratio analysis for authentication of lamb meat. Meat Science, v.64, p.239-247, 2003.

RENIERO, F.; ZILLER, L.; FRANCO, M.A.; DEL-CARO, A.; VACCA, V. Caratterizzazione dei mieli italiani di diversa provenienza (Trentino Alto-Adige e Sardegna) mediante il rapporto ${ }^{13} \mathrm{C} /{ }^{12} \mathrm{C}$. Rivista di Merceologia, v.31, n.1, p.39-48, 1997.

ROSSMANN, A.; HABERHAUER, G.; HOLZL, S.; HORN, P.; PICHLMAYER, F.; VOERKELIUS, S. The potential of multielement stable isotope analysis for regional origin assignment of butter. European Food Research \& Technology, v.211, p.32-40, 2000.

SERNAGIOTTO, E.S. Rastreabilidade da farinha de vísceras e aves em codornas submetidas a longo período de criação utilizando a técnica dos isótopos estáveis $\delta$ ${ }^{13} \mathbf{C}$ e $\boldsymbol{\delta}^{15} \mathbf{N}$. Tese (Mestrado em Zootecnia) - Faculdade de Medicina Veterinária e Zootecnia, Universidade Estadual Paulista, Botucatu. 2009.

SCHMIDT, O.; QUILTER, J.M; BAHAR, B.; MOLONEY, A.P.; SCRIMGEOUR, C.M.; BEGLEY, I.S.; MONAHAN, F.J. Inferring the origin and dietary history of beef from C, N and S stable analysis. Food Chemistry, v.91, p.545-549, 2005. 
SHIBUYA, E.K.; SARKIS, J.E.S.; NETO, O.N.; MOREIRA, M.Z.; VICTORIA, R.L. Souring Brazilian marijuana by applying IRMS analysis to seized samples. Forensic Science International, v.160, p.35-43, 2006.

SMITH, B.N.; EPSTEIN, S. Two categories of ${ }^{13} \mathrm{C} /{ }^{12} \mathrm{C}$ ratios of higher plants. Plant Physiology, v.47, p.380-384, 1971.

SPEARMAN, R.I.C. Integumentary System. In: Physiology and Biochemisrry of rhe Domestic Fowl. Ed. Bell and Freeman. Publ. Academic Press, London. 1971.

SPERS, E.E. Qualidade e segurança em alimentos. In: ZYLBERSZTAJN, D.; NEVES, M. F. (Orgs.). Economia e gestão de negócios agroalimentares. São Paulo: Pioneira, p.283-321, 2000.

TIESZEN L.L.; BOUTTON T.W.; TESDAHL K.G.; SLADE N.A. Fractionation and turnover of stable carbon isotopes in animal tissues: implications for $\delta^{13} \mathbf{C}$ analysis of diet. Oecologia, v.57, p.32-37, 1983.

THOMPSON, D.R.; BEARHOP, S.; SPEAKMAN, J.R.; FURNESS, R.W. Feathers as a means of monitoring mercury in seabirds:insights from stable isotope analysis. Environmental Pollution, v.101, p.193-200, 1998.

VAN DER MERVE, N.J. Carbon isotopes, photosynthesis and archaeology. American Scientist, New Haven, v.70, p.596-606, 1982. 
VOGEL, J.C. Variability of carbon isotope fractionation during photosynthesis. In: EHLERINGER, J. R.; HALL; A. E.; FAQUHAR, G. D. (ed). Stable isotopes and plant carbon-water relations. San Diego: Academic Press Inc., p.29-46, 1993.

VOIGT, C.C.; MATT, F.; MICHENER, R.; KUNZ, T.H. Low turnover rates of carbon isotopes in tissues of two nectar-feeding bat species. Institute for Zoo and Wildlife Research, Berlin, Germany, v.206, p. 119-1427. 2003.

WYATT, R.D.; HAMILTON, P.B.; BURMEISTER, H. R. Altered feathering of chicks caused hy T-2 Toxin. Poultry Science, v.54, p.1042-1045, 1975.

WHEELER, K.B.; LATSHAW, T.D. Sulfur amino acid requirements and interactions in broilers during two growth periods. Poultry Science, v.60, p.228-236, 1981.

WHITE, J.W.; WINTERS, K.; MARTIN, P.; ROSSMANN, A. Stable carbon isotope ratio analysis of honey: validation of internal standard procedure for worldwide application. Journal of the Association of Official Analytical Chemists International, v.81, p.610-619, 1998.

YALCIN, S.; SELTAR, P.; OZKAN, S.; CAHANER, A. Comparative evaluation of three commercial broiler stocks in hot vs. temperate climates. Poultry Science, v.76, p.921-929, 1997. 
CAPITULO 2 


\section{ISÓTOPOS ESTÁVEIS NA RASTREABILIDADE DE FARINHA DE ORIGEM ANIMAL NA ALIMENTAÇÃO DE FRANGOS DE CORTE}

\section{Resumo}

Existe a possibilidade de se detectar a utilização de subprodutos de origem animal em dietas de frango de corte por meio da aplicação técnica dos isótopos estáveis de carbono e nitrogênio em seus tecidos. O presente trabalho tem como objetivo analisar sangue e penas, para detectar a presença de farinha de vísceras (FV) na alimentação de frangos de corte por meio da técnica dos isótopos estáveis de carbono $\left({ }^{13} \mathrm{C} /{ }^{12} \mathrm{C}\right)$ e nitrogênio $\left({ }^{15} \mathrm{~N} /{ }^{14} \mathrm{~N}\right)$ por espectrometria de massas. Foram utilizados 720 pintos de corte machos, Cobb, submetidos aos tratamentos: ração vegetal à base de milho e farelo de soja de 1 a 42 dias de idade; ração com 8\% de farinha de vísceras de frango (FV) de 1 a 42 dias de idade; ração vegetal de 1 a 21 dias e ração com 8\% de FV de 22 a 42 dias; ração vegetal de 1 a 35 dias e ração com 8\% de FV de 36 a 42 dias; ração com 8\% de FV de 1 a 21 dias e ração vegetal de 22 a 42 dias; ração com 8\% de FV de 1 a 35 dias e ração vegetal de 36 a 42 dias. Foram colhidas amostras de penas do peito e de sangue de 4 aves/tratamentos aos 7, 14, 21, 28, 35 e 42 dias, as quais foram submetidas à análise isotópica. Para determinar o percentual estimado de participação da farinha de vísceras na composição desses tecidos, foi empregado o modelo de diluição isotópica de duas fontes e dois isótopos $\left({ }^{13} \mathrm{C}\right.$ e $\left.{ }^{15} \mathrm{~N}\right)$ na formação do produto. Os dados obtidos pela análise isotópica foram submetidos à análise multivariada de variância (MANOVA). Conclui que a aplicação da técnica dos isótopos estáveis de carbono e nitrogênio em penas de frango de corte pode detectar a utilização de farinha de vísceras na alimentação de frangos de corte por um período de até 21 dias após a retirada desse ingrediente da dieta, ou após 21 dias da inclusão da FV na dieta. No caso do sangue, o período máximo para detecção do uso da farinha de vísceras na dieta dos frangos é menor, de apenas 7 dias para frangos na fase inicial de criação, em função da elevada taxa de crescimento, e de 14 dias para frangos nas fases de crescimento e final.

Termos para indexação: carbono-13, certificação, farinha de vísceras, nitrogênio-15 


\title{
STABLE ISOTOPES IN TRACEABILITY OF ANIMAL MEAL FEEDING IN BROILERS
}

\begin{abstract}
Utilization of animal by-products in broilers diets can be detected by using the technique of the stable isotopes of carbon and nitrogen in their tissues. The present paper was aimed at detect the presence of poultry viscera meal (VM) in the diet of broilers, utilizing the technique of the stable isotopes of carbon $\left({ }^{13} \mathrm{C} /{ }^{12} \mathrm{C}\right)$ and nitrogen $\left({ }^{15} \mathrm{~N} /{ }^{14} \mathrm{~N}\right)$ by mass spectrometry, blood and feathers. We used 720 broiler chicks from Cobb, of treatments: vegetable diet based on corn and soybean meal from 1 -42 days old, diet with 8\% poultry viscera meal from 1-42 days, vegetable diet 1-21 days and diet with 8\% VM 22 -42 days, vegetable diet 1-35 days and diet with 8\%VM 36-42 days, diet with 8\%VM 1-21 days of vegetable diet and 22-42 days, diet with 8\% VM 1 -35 days of vegetable diet and 36 -42 days. Samples were collected breast feathers and blood of 4 birds / treatment at 7, 14, 21, 28, 35 and 42 days, which were submitted to isotopic analysis. To determine the estimated percentage of participation of poultry meal in the composition of these tissues, we used the model of isotopic dilution of two sources and two isotopes $\left({ }^{13} \mathrm{C}\right.$ and $\left.{ }^{15} \mathrm{~N}\right)$ in the formation of the product. The data obtained by isotopic analysis were submitted to multivariate analysis of variance (MANOVA) with the aid of the GLM procedure of SAS ${ }^{\circledR}$ (SAS Institute, 2000). We conclude that the technique of stable isotopes of carbon and nitrogen in feathers of broiler can detect the use of poultry viscera meal (VM) in feed for broiler for a period of up to 21 days after removal of this ingredient diet or 21 days after the inclusion of VM in the diet. In the case of blood, the maximum period to detect the use of poultry viscera meal in the diet of broilers is lower, only 7 days for broilers in the initial creation, due to the high growth rate, and 14 days for broilers in stages of growth and end.
\end{abstract}

Indexing terms: carbon-13, certification , nitrogen-15, poultry viscera meal 


\section{Introdução}

A avicultura brasileira destacou-se nas últimas décadas por uma trajetória de incremento tecnológico expressivo. A cadeia produtiva de frangos de corte assegura ao país uma posição de destaque no cenário mundial de produtores de carne de frango. $\mathrm{O}$ modelo de produção integrada de frango teve um grande sucesso, sendo responsável pelo crescimento e baixo custo de produção (Cima et al., 2006).

A inserção e a manutenção dos nossos produtos avícolas no mercado externo, em níveis competitivos e a maior demanda por produtos processados e as ocorrências de contaminações de alimentos e bebidas por patógenos ou resíduos, têm levado a modificações e reestruturação no setor produtivo de alimentos.

Estas modificações dependem da constante busca tanto da qualidade quanto do menor custo de produção. As barreiras sanitárias impostas pelos países importadores de carne de frango e os cuidados extremos, que começam na escolha da matéria-prima utilizada na alimentação das aves também influenciam. A maior preocupação será sempre prevenir a contaminação e a certificação desses produtos, porém, uma vez que a mesma já tenha ocorrido, os esforços são direcionados para minimizar ao máximo os efeitos e prejuízos dela decorrentes (Cima et al., 2006).

A segurança alimentar é a característica mais valorizada pelo consumidor no processo de escolha de um determinado produto. Os consumidores desejam transparência quanto às condições e aos métodos de produção do alimento. Eles estão interessados em saber como e onde os animais são criados, querem informações sobre sua alimentação, seu sistema de criação, entre outras. Com isso, surgiu o conceito de rastreabilidade, uma ferramenta para fornecer maior segurança ao consumidor (Silva, 2004). O termo rastreabilidade refere-se à capacidade de traçar o histórico, a aplicação ou a localização de um item através de informações previamente registradas. É importante atentar que sob o manto da rastreabilidade também podem aparecer outros interesses, além da qualidade, da segurança alimentar e da sanidade animal, podendo ser usados como barreira comercial, com o intuito de dificultar as exportações de um país (Rastreabilidade, 2004).

Para implantação dos programas de rastreabilidade, é fundamental conhecer as exigências dos consumidores para atendê-las da melhor maneira possível e com menor 
custo, por meio de um sistema que possa representar a realidade nacional. Além disso, a implantação do processo de rastreabilidade incentiva a integração das cadeias produtivas e, evidentemente, auxilia na conquista de novos mercados. A implantação destes sistemas está variando de país para país, de acordo com os hábitos alimentares dos consumidores e a sua classificação no mercado mundial como importador ou exportador. Também são diferentes as razões pelas quais os indivíduos, empresas e governos estão exigindo a implantação destes mecanismos, que têm um objetivo único: a segurança alimentar da população (Cima et al., 2006).

O único sistema de rastreabilidade oficialmente implantado é o de rastreamento na cadeia de bovinos e bubalinos, denominado Sisbov - Sistema Brasileiro de Identificação e Certificação de Origem Bovina e Bubalina. No entanto, o SISBOV foi criado em 2002 como uma resposta imediata do governo brasileiro às pressões da União Européia, que exigia um programa oficial de rastreabilidade para cadeia de bovinos (Rastreabilidade, 2004). Criado desde janeiro de 2002 e implantado desde julho de 2002, vem sendo ajustado ao longo dos últimos anos.

Muitos métodos têm sido propostos para identificar a presença de subprodutos de origem animal em rações para animais, tais como, hibridização de DNA, ELISA e PCR (Block Junior, 2002). A espectrometria de massas, através da análise da razão isotópica para o elemento químico do carbono-13, tem sido usada com sucesso para testar a autenticidade, a qualidade e a origem geográfica de vários produtos, tais como: suco de frutas (Bricout \& Koziet, 1987; Koziet et al., 1993), vinhos (Martin et al., 1988), méis (Brookes et al., 1991; White et al., 1998), produtos lácteos (Rossmann et al., 2000; Manca et al., 2001), óleos vegetais (Kelly et al., 1997).

Com o desenvolvimento da técnica dos isótopos estáveis para fins de rastreabilidade e certificação do padrão dietético de frangos de corte, surgiu a necessidade de se conhecer o comportamento da assinatura isotópica de diferentes tecidos nas aves, por ocasião de uma eventual substituição de dieta contendo ingrediente de origem animal por dieta estritamente vegetal, e vice-versa Oliveira (2005).

O presente trabalho teve como objetivo analisar sangue e penas, para detectar a presença de farinha de vísceras (FV) na alimentação de frangos de corte por meio da técnica dos isótopos estáveis de carbono $\left({ }^{13} \mathrm{C} /{ }^{12} \mathrm{C}\right)$ e nitrogênio $\left({ }^{15} \mathrm{~N} /{ }^{14} \mathrm{~N}\right)$ por espectrometria de massas. 


\section{Material e Métodos}

O experimento foi conduzido na Faculdade de Medicina Veterinária e Zootecnia UNESP - Campus de Botucatu, nas instalações do Laboratório de Nutrição de Aves. Foram utilizados 720 pintainhos de corte machos, da linhagem Cobb, com um dia, distribuídos em um delineamento em blocos casualizados com 6 tratamentos e 4 repetições, sendo criadas em galpão experimental dividido em 24 boxes de 2,5 $\mathrm{m}^{2}$, com 30 aves/boxe, em uma densidade de 12 aves $/ \mathrm{m}^{2}$, em piso. As aves previamente vacinadas contra Gumboro, Marek e Bouba aviária, foram criadas até os 42 dias de idade e vacinadas contra Gumboro, via água de bebida, aos 10 e 20 dias de idade.

Inicialmente cada boxe continha um bebedouro tipo copo de pressão para o fornecimento de água, e um comedouro tipo tubular inicial para o fornecimento da ração. Estes equipamentos foram substituídos gradativamente por bebedouro pendular e comedouro tubular definitivos, um para cada boxe, respectivamente. O fornecimento de água e ração foi ad libitum durante todo o período experimental. Para aquecimento inicial dos pintos, cada boxe foi equipado com uma campânula com lâmpada infravermelha de 250 watts, que foi retirada no sétimo dia de idade dos pintos.

O programa de arraçoamento foi dividido em duas fases: 1 a 21 dias (Tabela 1) e 22 a 42 dias (Tabela 2). As rações foram elaboradas para serem isoprotéicas e isoenergéticas, sendo formuladas à base de milho, farelo de soja, óleo de soja, fosfato bicálcico, calcário calcítico, sal comum, DL-metionina, L-lisina e suplementos vitamínico e mineral, conforme adaptações das recomendações de Rostagno et al. (2005). A porcentagem de inclusão de FV na dieta foi estipulada em $8 \%$, de acordo com informações a respeito de níveis práticos adotados, colhidas junto a empresas produtoras de frangos de corte. 
Tabela 1. Composição percentual e teores nutricionais calculados para as rações experimentais 1 a 21 dias de idade.

\begin{tabular}{|c|c|c|}
\hline \multirow[t]{2}{*}{ Ingredientes, \% } & \multicolumn{2}{|c|}{ Farinha de Vísceras, \% } \\
\hline & 0,0 & 8,0 \\
\hline Milho, grão & 57,70 & 65,16 \\
\hline Soja, farelo & 35,56 & 23,90 \\
\hline Vísceras, farinha & 0,00 & 8,00 \\
\hline Soja, óleo & 2,64 & 0,10 \\
\hline Calcário calcítico & 0,98 & 0,82 \\
\hline Fosfato bicálcico & 1,83 & 0,80 \\
\hline DL - Metionina & 0,23 & 0,20 \\
\hline L - Lisina & 0,16 & 0,22 \\
\hline Colina, cloreto (70\%) & 0,04 & 0,04 \\
\hline Sal comum & 0,46 & 0,36 \\
\hline Suplemento vitamínico-mineral ${ }^{1}$ & 0,40 & 0,40 \\
\hline Total & 100 & 100 \\
\hline \multicolumn{3}{|l|}{ Níveis Nutricionais Calculados } \\
\hline Energia metabolizável, kcal/kg & 3000 & 3000 \\
\hline Proteína bruta, \% & 21,40 & 21,40 \\
\hline Cálcio, \% & 0,96 & 0,96 \\
\hline Fósforo disponível, \% & 0,45 & 0,45 \\
\hline Metionina, \% & 0,56 & 0,56 \\
\hline Metionina + cistina, \% & 0,90 & 0,90 \\
\hline Lisina, \% & 1,26 & 1,26 \\
\hline
\end{tabular}


Tabela 2. Composição percentual dos ingredientes, teores nutricionais calculados para as rações experimentais de 22 a 42 dias de idade.

\begin{tabular}{|c|c|c|}
\hline \multirow{2}{*}{ Ingrediente, \% } & \multicolumn{2}{|c|}{ Farinha de Vísceras, \% } \\
\hline & 0,0 & 8,0 \\
\hline Milho, grão & 63,25 & 70,66 \\
\hline Soja, farelo & 29,82 & 18,18 \\
\hline Vísceras, farinha & 0,00 & 8,00 \\
\hline Soja, óleo & 3,11 & 0,59 \\
\hline Calcário calcítico & 0,94 & 0,77 \\
\hline Fosfato bicálcico & 1,63 & 0,60 \\
\hline DL - Metionina & 0,22 & 0,18 \\
\hline L - Lisina & 0,22 & 0,28 \\
\hline Colina, cloreto (70\%) & 0,04 & 0,04 \\
\hline Sal comum & 0,38 & 0,30 \\
\hline Suplemento vitamínico-mineral $^{1}$ & 0,40 & 0,40 \\
\hline Total & 100 & 100 \\
\hline \multicolumn{3}{|l|}{ Níveis Nutricionais Calculados } \\
\hline Energia metabolizável, kcal/kg & 3100 & 3100 \\
\hline Proteína bruta, \% & 19,30 & 19,30 \\
\hline Cálcio, \% & 0,88 & 0,88 \\
\hline Fósforo disponível, \% & 0,41 & 0,41 \\
\hline Metionina, \% & 0,51 & 0,51 \\
\hline Metionina + cistina, \% & 0,83 & 0,83 \\
\hline Lisina, \% & 1,16 & 1,16 \\
\hline
\end{tabular}

As aves foram submetidas a seis tratamentos experimentais de acordo com os seguintes grupos:

RV (1-42d)- ração vegetal à base de milho e farelo de soja, sem subproduto de origem animal de 1 a 42 dias de idade;

FV (1-42d)- ração com 8\% de farinha de vísceras de frango (FV) de 1 a 42 dias de idade;

FV (22-42d)- ração vegetal de 1 a 21 dias e ração com 8\% de FV de 22 a 42 dias de idade;

FV (35-42d)- ração vegetal de 1 a 35 dias e ração com 8\% de FV de 35 a 42 dias de idade; 
FV (1-21d)- ração com 8\% de FV de 1 a 21 dias e ração vegetal de 22 a 42 dias de idade;

FV (1-35d)- ração com 8\% de FV de 1 a 35 dias e ração vegetal de 36 a 42 dias de idade.

A cada coleta (aos 7, 14, 21, 28, 35 e 42 dias de idade), foram tomadas aleatoriamente 4 aves/tratamento, das quais foram colhidas amostras de sangue e penas. As amostras de sangue foram colhidas da veia braquial, da asa esquerda, com seringa e agulha descartável. O sangue foi armazenado em tubo de plástico descartável identificado e congelado a $-18^{\circ} \mathrm{C}$. As penas foram retiradas manualmente da região do peito e devidamente identificadas e acondicionadas em embalagens individuais, e também congeladas, para posterior análise isotópica, conforme a Figura 1.

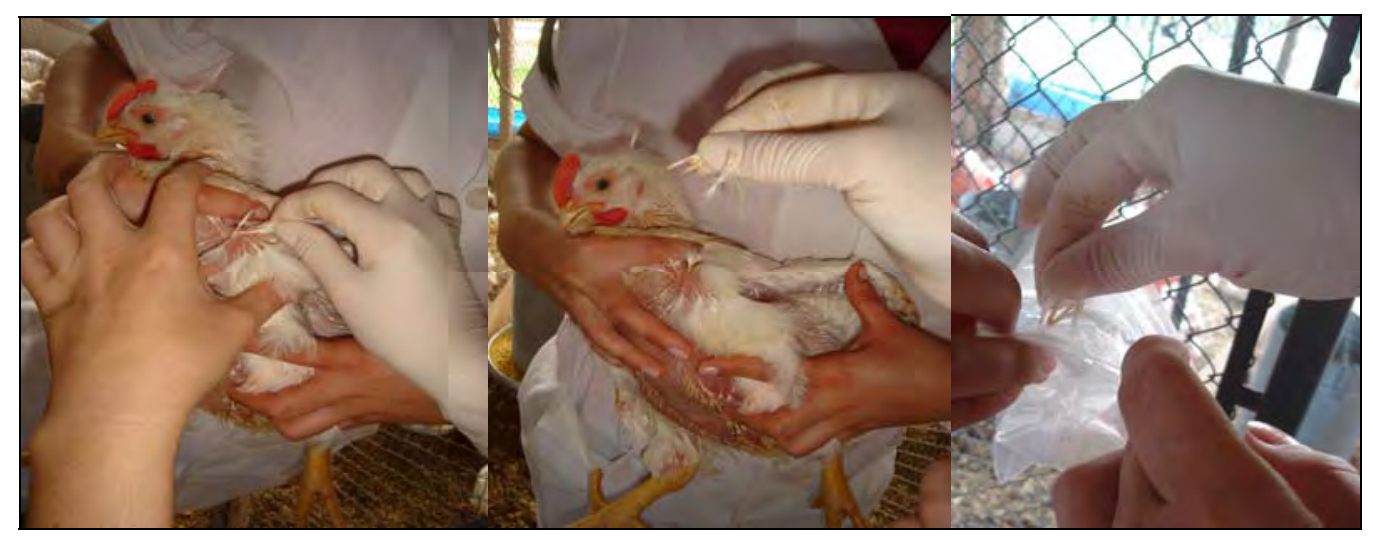

FIGURA 1. Coleta de penas.

As análises isotópicas das amostras de sangue, penas e rações foram realizadas na UNESP, Campus de Botucatu, no Centro de Isótopos Estáveis Ambientais do Instituto de Biociências (CIE/IB).

Para realização dessas análises, as amostras de sangue foram apenas descongeladas, e foram analisadas na forma líquida, adicionando-se 0,2 $\mu \mathrm{l}$ e 0,3 $\mu \mathrm{l}$ em cápsulas de estanho, para as medidas das razões isotópicas de ${ }^{13} \mathrm{C} /{ }^{12} \mathrm{C}$ e ${ }^{15} \mathrm{~N} /{ }^{14} \mathrm{~N}$, respectivamente. As amostras das penas foram descongeladas e lavadas em água destilada para remover qualquer contaminação de ração e fezes, em seguida, foram secas em estufa de ventilação forçada, à temperatura de $50^{\circ} \mathrm{C}$ por 24 horas. Sobre uma placa de petri foram cortadas finamente com tesoura e lamina até que ficasse o mais homogêneo possível. Foram pesadas em cápsulas de estanho, aproximadamente 50 a 60 
$\mu \mathrm{g}$ e 500 a $600 \mu \mathrm{g}$ de amostras para a determinação das razões isotópicas do carbono e nitrogênio, respectivamente. As cápsulas foram introduzidas por meio de amostrador automático no analisador elementar (EA 1108 - CHN - Fisons Instruments, Rodano, Itália) no qual, em presença de oxigênio $\left(\mathrm{O}_{2}\right)$ e óxido de cobre $(\mathrm{CuO})$ a amostra foi queimada quantitativamente para a obtenção de $\mathrm{CO}_{2}$ e $\mathrm{NOx}$; este último foi então reduzido a $\mathrm{N}_{2}$ na presença de cobre. Os gases formados foram separados em coluna cromatográfica gasosa e analisados no espectrômetro de massas de razões isotópicas (Delta S - Finnigan MAT, Bremen, Alemanha).

Os resultados das análises foram expressos em delta per mil ( $\delta \%$ ) relativos aos padrões internacionais: Peedee Belemnite (PDB) para $0{ }^{13} \mathrm{C}$ e nitrogênio do ar atmosférico para ${ }^{15} \mathrm{~N}$, de acordo com a seguinte equação geral:

$$
\delta \text { X (amostra, padrão) }=[(\text { Ramostra }- \text { Rpadrão }) / \text { Rpadrão }] \text { x } 1000
$$

Onde:

$\delta \mathrm{X}=$ enriquecimento do isótopo mais pesado do elemento químico $\mathrm{X}(\mathrm{C}$ ou $\mathrm{N})$ da amostra em relação ao respectivo padrão internacional.

$\mathrm{R}=$ razão isotópica entre o isótopo menos e o mais abundante, ${ }^{13} \mathrm{C} /{ }^{12} \mathrm{C} \mathrm{e}{ }^{15} \mathrm{~N} /{ }^{14} \mathrm{~N}$.

Os resultados isotópicos obtidos foram submetidos à análise multivariada de variância (MANOVA) com auxílio do procedimento GLM do programa estatístico SAS (1996). A partir dos dados gerados pelas matrizes de erro, foram determinadas regiões com 95\% de confiança para verificar as diferenças entre as médias dos tratamentos.

\section{Resultados e Discussão}

Os resultados das análises isotópicas $\left(\delta^{13} \mathrm{C}\right.$ e $\left.\delta^{15} \mathrm{~N}\right)$ das rações utilizadas neste estudo estão contidos na Tabela 3. Observou-se que os valores de $\delta^{15} \mathrm{~N}$ enriqueceram tanto da dieta vegetal (0\%) para a dieta com FV (8\%), como das rações 1 a 21 dias de idade para as rações de 22 a 42 dias de idade dentro de uma mesma dieta. Isso ocorreu, provavelmente, devido às variações na composição percentual dos ingredientes nas rações. As rações da dieta com FV continham menor quantidade de farelo de soja e maiores quantidades de milho e FV em relação às rações da dieta vegetal. $\mathrm{O}$ enriquecimento semelhante observado das rações de 1 a 21 para as rações de 22 a 42 
pode ser atribuído ao mesmo fato, pois as rações de 22 a 42 também continham menor percentual de farelo de soja. Os ingredientes milho $\left(\delta^{13} \mathrm{C}=-12,15 \% \pm 0,04\right.$ e $\delta^{15} \mathrm{~N}=$ $6,81 \%$ \% $\pm 0,04)$, farelo de soja $\left(\delta^{13} \mathrm{C}=-26,15 \%\right.$ o $\pm 0,10$ e $\delta^{15} \mathrm{~N}=0,55 \%$ o $\left.\pm 0,04\right)$ e farinha de vísceras $\left(\delta^{13} \mathrm{C}=-16,85 \% \pm 0,13\right.$ e $\left.\delta^{15} \mathrm{~N}=4,07 \% \pm 0,10\right)$, utilizados na confecção das rações, também foram analisados isotopicamente para nitrogênio e carbono. Sabe-se que a soja possui valor de $\delta^{15} \mathrm{~N}$ que se aproxima ao valor do padrão de $\mathrm{N}_{2}$ atmosférico ( $\delta^{15} \mathrm{~N}=0,0 \pm 1,0 \%$ ), pois fixam o nitrogênio do ar e apresentam fator de fracionamento de $\delta^{15} \mathrm{~N}$ ao redor de uma unidade, ficando geralmente abaixo de 1,003\% (KOHL \& SHEARER, 1980; HANDLEY \& RAVEN, 1992; WERNER \& SCHMIDT, 2002). Já o valor de $\delta^{15} \mathrm{~N}$ apresentado por plantas que não conseguem fixar o nitrogênio atmosférico depende, em grande parte, da abundância desse isótopo no solo e adubos administrados, como é o caso do milho (CHOI et al., 2002). SLEIMAN et al. (2004), avaliando amostras de milho de alguns estados brasileiros, encontraram valores médios de 4,77 \pm 1,16\% para $\delta^{15} \mathrm{~N}$, e $-11,74 \pm 0,40$ para $\delta^{13} \mathrm{C}$, respectivamente.

A exemplo do enriquecimento ocorrido nos valores de $\delta^{15} \mathrm{~N}$ descrito acima, o mesmo foi observado para os valores de $\delta^{13} \mathrm{C}$ nas rações experimentais. Pois, ao se incluir FV na formulação da ração, menor quantidade de farelo e óleo de soja foi requerida para o seu balanceamento em relação à ração vegetal isoenergética e isoprotéica correspondente. Além disso, aumentou-se a inclusão do ingrediente energético, nesse caso, o milho. Isso acontece, porque plantas do ciclo fotossintético $\mathrm{C}_{3}$ (ex.: soja, arroz, trigo) possuem um valor modal de $\delta^{13} \mathrm{C}=-27,6 \%$ em relação ao padrão $P D B$, e nas plantas do ciclo fotossintético $\mathrm{C}_{4}$ (ex.: milho, sorgo, cana-de-açúcar), esse valor modal é de $\delta^{13} \mathrm{C}=-12,6 \%$ (VOGEL, 1993). As rações de 22 a 42 dias seriam mais ricas em ${ }^{13} \mathrm{C}$ em relação às rações 1 a 21 dias, pois em termos nutricionais, são mais energéticas e menos protéicas, fazendo com que a composição percentual dos ingredientes mude dentro da mesma dieta, embora esses valores possam não apresentar diferenças significativas. Para tanto, as rações de 22 a 42 dias teriam maior quantidade de milho e menor quantidade de farelo de soja.

Esses apontamentos relativos aos valores de $\delta^{13} \mathrm{C}$ e $\delta^{15} \mathrm{~N}$ das rações de frangos de corte, assim como de outras espécies, mostram-se fundamentais para a identificação da presença de subprodutos de origem animal na alimentação, uma vez que a assinatura isotópica da dieta é refletida no organismo dos animais. Segundo DeNIRO \& EPSTEIN 
(1976; 1978), o animal é aquilo que consome isotopicamente, até $\pm 2,0 \%$ para $\delta^{13} \mathrm{C}$ e até $\pm 3,0 \%$ para $\delta^{15} \mathrm{~N}$, embora cada tecido de um mesmo animal possa apresentar particular assinatura isotópica, fator de fracionamento (HOBSON \& CLARK, 1992b) e turnover isotópico (HOBSON \& CLARK, 1992a).

Tabela 3. Valores isotópicos médios de $\delta^{13} \mathrm{C}$ e $\delta^{15} \mathrm{~N}$ da ração, e seus desvios-padrão, da ração de frangos de corte criados até os 42 dias de idade.

\begin{tabular}{lccc}
\hline & Inclusão de FV & & \\
RAÇÃO & $(\%)$ & $\delta^{13} \mathrm{C}^{1} \mathrm{D} . \mathrm{P}$ & $\delta^{15} \mathrm{~N}^{1} \mathrm{D} . \mathrm{P}$ \\
\hline Inicial & 0,0 & $-17,72 \pm 0,25$ & $1,75 \pm 0,18$ \\
(1 a 21 dias de idade) & 8,0 & $-16,22 \pm 0,10$ & $2,67 \pm 0,11$ \\
Crescimento & 0,0 & $-17,09 \pm 0,16$ & $1,85 \pm 0,24$ \\
(22 a 42 dias de idade) & 8,0 & $-15,76 \pm 0,07$ & $3,26 \pm 0,10$ \\
\hline
\end{tabular}

${ }^{1}$ Valores isotópicos médios expressos em $\delta^{13} \mathrm{C}$ e $\delta^{15} \mathrm{~N}$ relativos aos padrões PeeDee Belemnite (PDB) e nitrogênio atmosférico $\left(\mathrm{N}_{2}\right)$, respectivamente.

Os valores médios de $\delta^{13} \mathrm{C}$ e $\delta^{15} \mathrm{~N}$ para penas e sangue dos frangos de corte estão contidos na Tabela 4 e 5. 
Tabela 4. Valores médios de $\delta^{13} \mathrm{C}$ e $\delta^{15} \mathrm{~N}$, e seus desvios-padrão, das penas de frangos de corte criados até os 42 dias de idade.

\begin{tabular}{|c|c|c|c|}
\hline Idade & TRATAMENTO $^{1}$ & $\delta^{13} \mathrm{C} \pm \mathrm{DP}$ & $\delta^{15} \mathrm{~N} \pm \mathrm{DP}$ \\
\hline \multirow[t]{4}{*}{7 dias } & RV 1-42d & $-18,6 \pm 0,20$ & $5,86 \pm 0,33$ \\
\hline & FV 1-42d & $-17,77 \pm 0,22$ & $6,11 \pm 0,13$ \\
\hline & FV 1-35d & $-17,97 \pm 0,10$ & $6,19 \pm 0,08$ \\
\hline & FV 1-21d & $-17,65 \pm 0,22$ & $6,14 \pm 0,14$ \\
\hline \multirow[t]{4}{*}{14 dias } & RV 1-42d & $-18,07 \pm 0,31$ & $5,65 \pm 0,23$ \\
\hline & FV 1-42d & $-17,41 \pm 0,27$ & $6,18 \pm 0,25$ \\
\hline & FV 1-35d & $-17,70 \pm 0,14$ & $6,11 \pm 0,30$ \\
\hline & FV 1-21d & $-17,62 \pm 0,07$ & $5,88 \pm 0,18$ \\
\hline \multirow[t]{4}{*}{21 dias } & RV 1-42d & $-18,94 \pm 0,11$ & $3,32 \pm 0,05$ \\
\hline & FV 1-42d & $-16,89 \pm 0,13$ & $4,64 \pm 0,07$ \\
\hline & FV 1-35d & $-17,16 \pm 0,10$ & $4,65 \pm 0,09$ \\
\hline & FV 1-21d & $-17,23 \pm 0,15$ & $4,39 \pm 0,15$ \\
\hline \multirow[t]{5}{*}{28 dias } & RV 1-42d & $-18,57 \pm 0,20$ & $3,62 \pm 0,07$ \\
\hline & FV 1-42d & $-16,94 \pm 0,21$ & $4,68 \pm 0,08$ \\
\hline & FV 1-35d & $-17,14 \pm 0,17$ & $4,73 \pm 0,10$ \\
\hline & FV 1-21d & $-17,85 \pm 0,18$ & $4,16 \pm 0,06$ \\
\hline & FV 22-42d & $-18,06 \pm 0,26$ & $3,93 \pm 0,21$ \\
\hline \multirow[t]{5}{*}{35 dias } & RV 1-42d & $-18,85 \pm 0,07$ & $3,81 \pm 0,12$ \\
\hline & FV 1-42d & $-16,92 \pm 0,11$ & $4,97 \pm 0,08$ \\
\hline & FV 1-35d & $-16,85 \pm 0,28$ & $4,97 \pm 0,09$ \\
\hline & FV 1-21d & $-17,93 \pm 0,17$ & $4,14 \pm 0,16$ \\
\hline & FV 22-42d & $-17,75 \pm 0,26$ & $4,36 \pm 0,18$ \\
\hline \multirow[t]{6}{*}{42 dias } & RV 1-42d & $-18,65 \pm 0,20$ & $3,87 \pm 0,21$ \\
\hline & FV 1-42d & $-16,92 \pm 0,26$ & $5,07 \pm 0,12$ \\
\hline & FV 1-35d & $-17,04 \pm 0,06$ & $4,59 \pm 0,05$ \\
\hline & FV 1-21d & $-18,24 \pm 0,09$ & $4,10 \pm 0,11$ \\
\hline & FV 22-42d & $-17,29 \pm 0,26$ & $4,93 \pm 0,08$ \\
\hline & FV 35-42d & $-18,62 \pm 0,01$ & $3,82 \pm 0,11$ \\
\hline
\end{tabular}

${ }^{1}$ RV 1-42d- ração vegetal à base de milho e farelo de soja, sem subproduto de origem animal (ração basal) de 1 a 42 dias de idade; FV 1-42d- ração com 8\% de farinha de vísceras de frango (FV) de 1 a 42 dias de idade; FV 1-35dração com $8 \%$ de FV de 1 a 35 dias e ração basal de 35 a 42 dias de idade; FV 1-21d- ração com 8\% de FV de 1 a 21 dias e ração basal de 22 a 42 dias de idade;. FV 22-42d- ração basal de 1 a 21 dias e ração com 8\% de FV de 22 a 42 dias de idade; FV 35-42d- ração basal de 1 a 35 dias e ração com 8\% de FV de 35 a 42 dias de idade. 
Tabela 5. Valores médios de $\delta^{13} \mathrm{C}$ e $\delta^{15} \mathrm{~N}$, e seus desvios-padrão, de sangue de frangos de corte criados até os 42 dias de idade.

\begin{tabular}{|c|c|c|c|}
\hline Idade & TRATAMENTO $^{1}$ & $\delta^{13} \mathrm{C} \pm \mathrm{DP}$ & $\delta^{15} \mathrm{~N} \pm \mathrm{DP}$ \\
\hline \multirow[t]{4}{*}{7 dias } & RV 1-42d & $-19,94 \pm 0,11$ & $3,34 \pm 0,13$ \\
\hline & FV 1-42d & $-18,52 \pm 0,16$ & $4,08 \pm 0,08$ \\
\hline & FV 1-35d & $-18,83 \pm 0,16$ & $3,96 \pm 0,15$ \\
\hline & FV 1-21d & $-18,62 \pm 0,17$ & $4,15 \pm 0,28$ \\
\hline \multirow[t]{4}{*}{14 dias } & RV 1-42d & $-20,68 \pm 0,13$ & $2,75 \pm 0,07$ \\
\hline & FV 1-42d & $-18,91 \pm 0,14$ & $3,6 \pm 0,11$ \\
\hline & FV 1-35d & $-18,9 \pm 0,13$ & $3,58 \pm 0,14$ \\
\hline & FV 1-21d & $-18,87 \pm 0,22$ & $3,57 \pm 0,14$ \\
\hline \multirow[t]{4}{*}{21 dias } & RV 1-42d & $-20,74 \pm 0,24$ & $2,79 \pm 0,17$ \\
\hline & FV 1-42d & $-18,89 \pm 0,09$ & $3,78 \pm 0,11$ \\
\hline & FV 1-35d & $-19,19 \pm 0,22$ & $3,85 \pm 0,17$ \\
\hline & FV 1-21d & $-18,91 \pm 0,30$ & $3,58 \pm 0,15$ \\
\hline \multirow[t]{5}{*}{28 dias } & RV 1-42d & $-20,47 \pm 0,19$ & $3,02 \pm 0,23$ \\
\hline & FV 1-42d & $-18,80 \pm 0,25$ & $3,95 \pm 0,07$ \\
\hline & FV 1-35d & $-19,09 \pm 0,19$ & $3,83 \pm 0,15$ \\
\hline & FV 1-21d & $-19,39 \pm 0,23$ & $3,39 \pm 0,26$ \\
\hline & FV 22-42d & $-19,75 \pm 0,09$ & $3,35 \pm 0,10$ \\
\hline \multirow[t]{5}{*}{35 dias } & RV 1-42d & $-20,15 \pm 0,19$ & $3,22 \pm 0,16$ \\
\hline & FV 1-42d & $-18,41 \pm 0,09$ & $3,97 \pm 0,31$ \\
\hline & FV 1-35d & $-18,27 \pm 0,05$ & $4,09 \pm 0,05$ \\
\hline & FV 1-21d & $-19,40 \pm 0,16$ & $3,36 \pm 0,16$ \\
\hline & FV 22-42d & $-18,84 \pm 0,15$ & $3,77 \pm 0,37$ \\
\hline \multirow[t]{6}{*}{42 dias } & RV 1-42d & $-20,19 \pm 0,07$ & $4,01 \pm 0,07$ \\
\hline & FV 1-42d & $-18,21 \pm 0,11$ & $4,06 \pm 0,07$ \\
\hline & FV 1-35d & $-18,58 \pm 0,15$ & $3,64 \pm 0,22$ \\
\hline & FV 1-21d & $-19,44 \pm 0,15$ & $3,02 \pm 0,20$ \\
\hline & FV 22-42d & $-18,51 \pm 0,21$ & $3,84 \pm 0,14$ \\
\hline & FV 35-42d & $-19,48 \pm 0,19$ & $2,77 \pm 0,19$ \\
\hline
\end{tabular}

${ }^{1} \mathrm{RV} 1$-42d- ração vegetal à base de milho e farelo de soja, sem subproduto de origem animal (ração basal) de 1 a 42 dias de idade; FV 1-42d- ração com 8\% de farinha de vísceras de frango (FV) de 1 a 42 dias de idade; FV 1-35dração com 8\% de FV de 1 a 35 dias e ração basal de 35 a 42 dias de idade; FV 1-21d- ração com 8\% de FV de 1 a 21 dias e ração basal de 22 a 42 dias de idade;. FV 22-42d- ração basal de 1 a 21 dias e ração com 8\% de FV de 22 a 42 dias de idade; FV 35-42d- ração basal de 1 a 35 dias e ração com 8\% de FV de 35 a 42 dias de idade. 
As Figuras 2, 3, 4, 5, 6 e 7 mostram as regiões (elipses) com 95\% de confiança para verificação das diferenças entre as médias dos pares isotópicos $\left(\delta^{13} \mathrm{C}\right.$ e $\left.\delta^{15} \mathrm{~N}\right)$ dos tratamentos no tecido, comparados com o grupo controle (dieta vegetal).

Os tratamentos diferem do tratamento controle (RV 1-42d) quando a diferença entre suas médias de $\delta^{13} \mathrm{C}$ e $\delta^{15} \mathrm{~N}$ forem diferentes de zero, e assim, a região de confiança não sobrepor a nenhum dos eixos do gráfico. O fato das elipses sobreporem um dos eixos mostra que na há diferença entre médias de $\delta^{13} \mathrm{C}$ e $\delta^{15} \mathrm{~N}$ dos tratamentos comparados com o controle (RV 1-42d).

Observando a Figura 2 foi possível se notar que, aos 7 dias de idade, no sangue, as aves do tratamento que receberam dieta com $8 \%$ de FV durante todo o período experimental, e as aves dos tratamento que receberam FV1-21d e FV1-35d, diferiram do tratamento vegetal, pois suas regiões de confiança não sobrepuseram nenhum dos eixos no gráfico; para as penas, estes tratamentos não diferiram do tratamento vegetal, pois suas elipses sobrepuseram ao eixo das diferenças de $\delta^{13}$ C. Esse fato ocorreu provavelmente, devido ao fato de que as penas, aos 7 dias de idade, não terem sido trocadas (penugem) e, assim, ainda estavam trazendo o sinal isotópico da matriz. Não foram analisadas sangue e penas das aves dos tratamentos FV22-42d e FV35-42d, devido aos mesmo ainda não terem se iniciado, neste período.

Na Figura 3, observa-se que aos 14 dias de idade, para as penas, as dietas com 8\% FV ainda não diferiram da dieta vegetal, sendo que este período ainda não foi suficiente para incorporar o sinal isotópico da alimentação nas penas. O sangue permaneceu com o mesmo comportamento observados aos 7 dias. A Figura 4 mostra que com 21 dias as penas das aves foram capazes de incorporar o sinal isotópico dos tratamentos que receberam dieta com 8\% de farinha de vísceras (FV1-42d, FV1-21d e FV1-35d), sendo que o período de 21 dias foi suficiente para incorporação do sinal nas penas. 

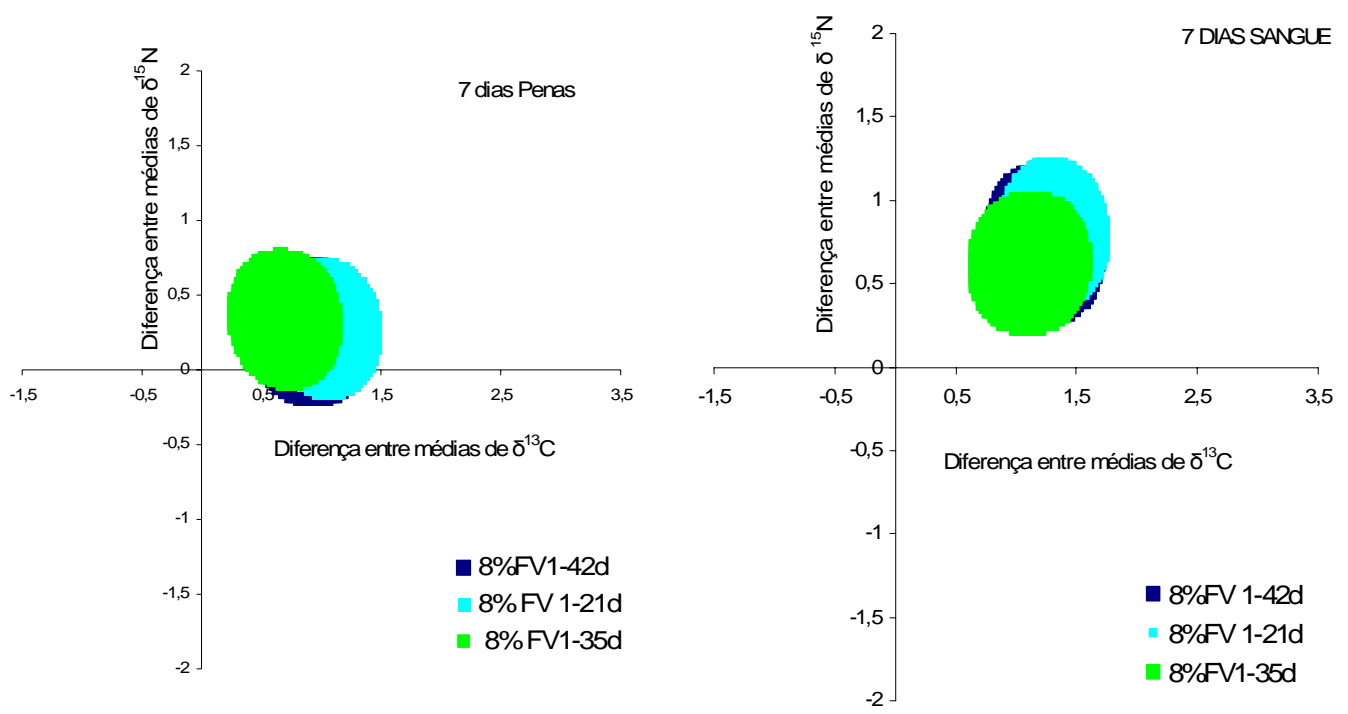

FIGURA 2. Regiões de confiança formadas pela diferença entre os valores isotópicos de $\delta^{13} \mathrm{C}$ e $\delta^{15} \mathrm{~N}$ de penas e sangue de frangos de corte aos 7 dias de idade de cada tratamento quando comparados ao tratamento controle.
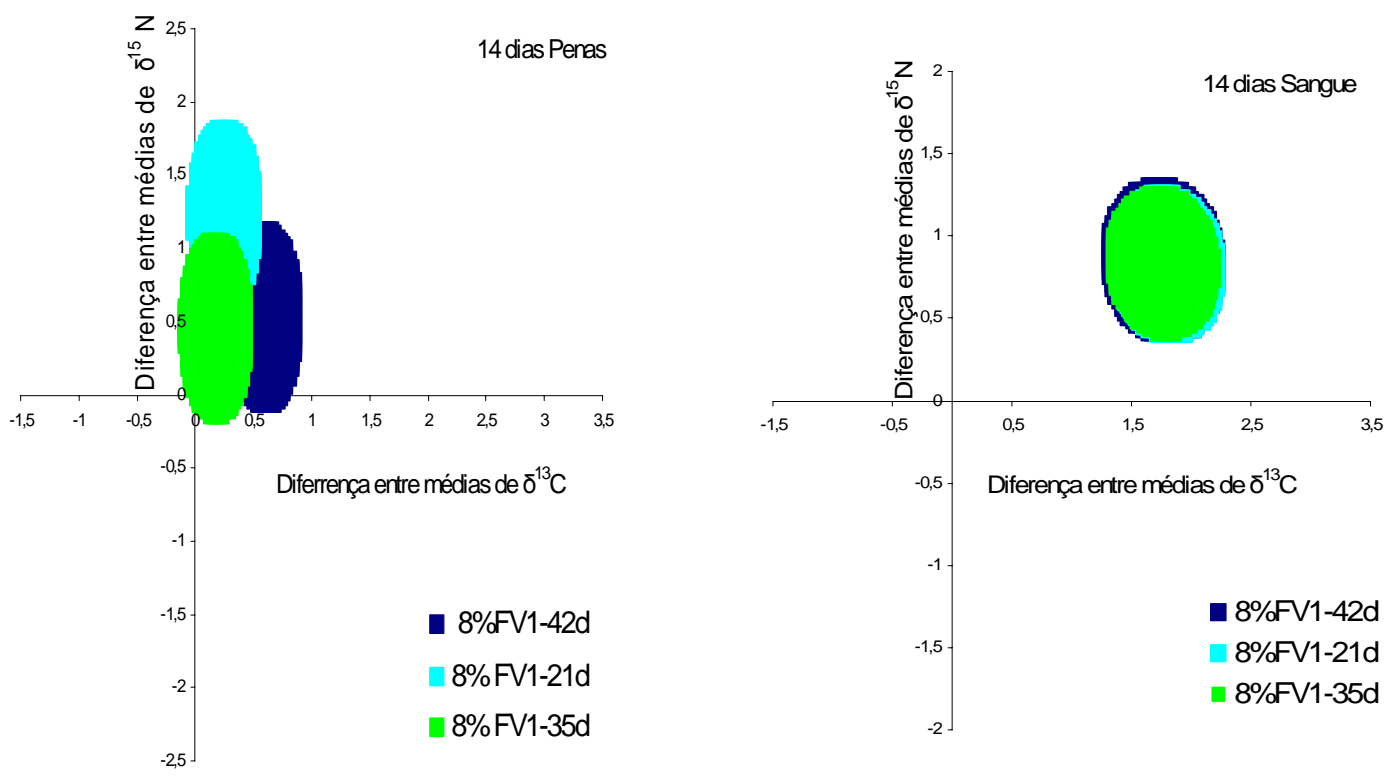

FIGURA 3. Regiões de confiança formadas pela diferença entre os valores isotópicos de $\delta^{13} \mathrm{C}$ e $\delta^{15} \mathrm{~N}$ de penas e sangue de frangos de corte aos 14 dias de idade de cada tratamento quando comparados ao tratamento controle. 

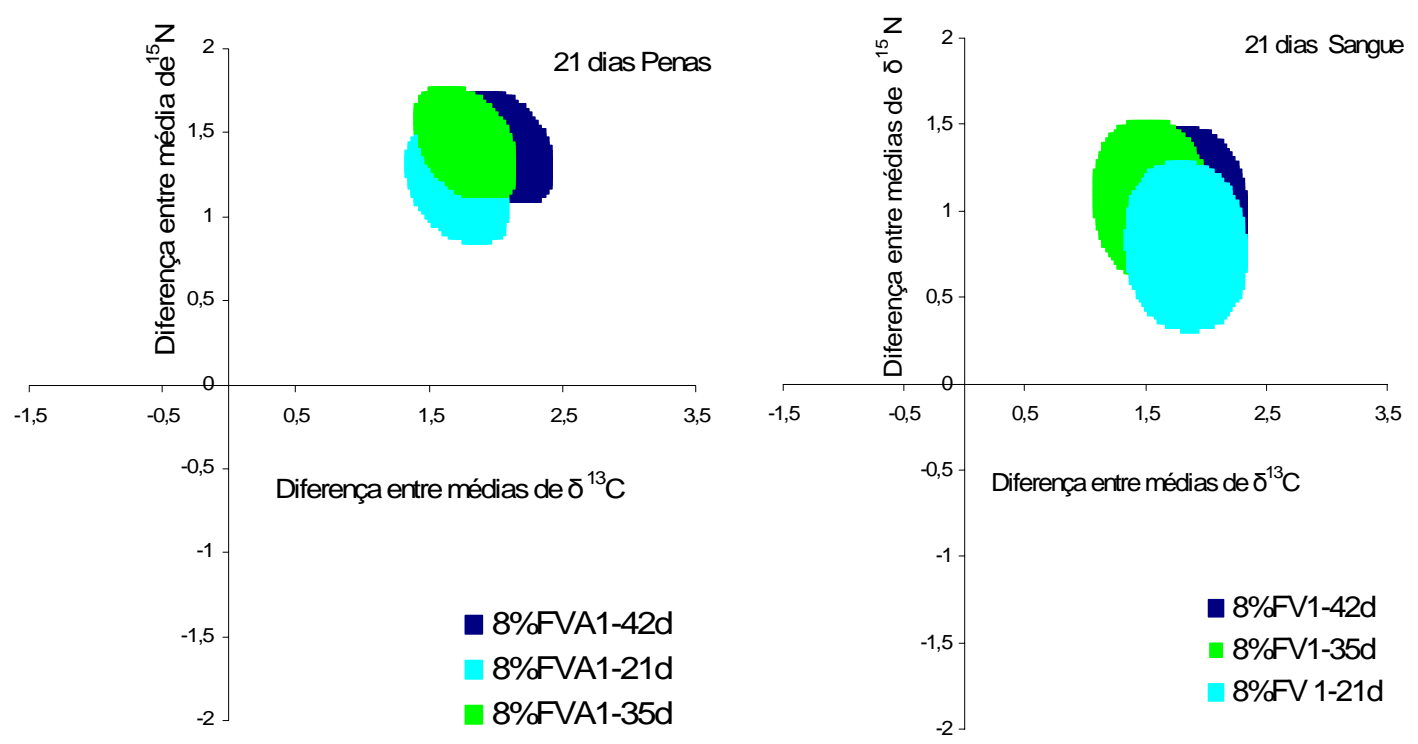

FIGURA 4. Regiões de confiança formadas pela diferença entre os valores isotópicos de $\delta^{13} \mathrm{C}$ e $\delta^{15} \mathrm{~N}$ de penas e sangue de frangos de corte aos 21 dias de idade de cada tratamento quando comparados ao tratamento controle.
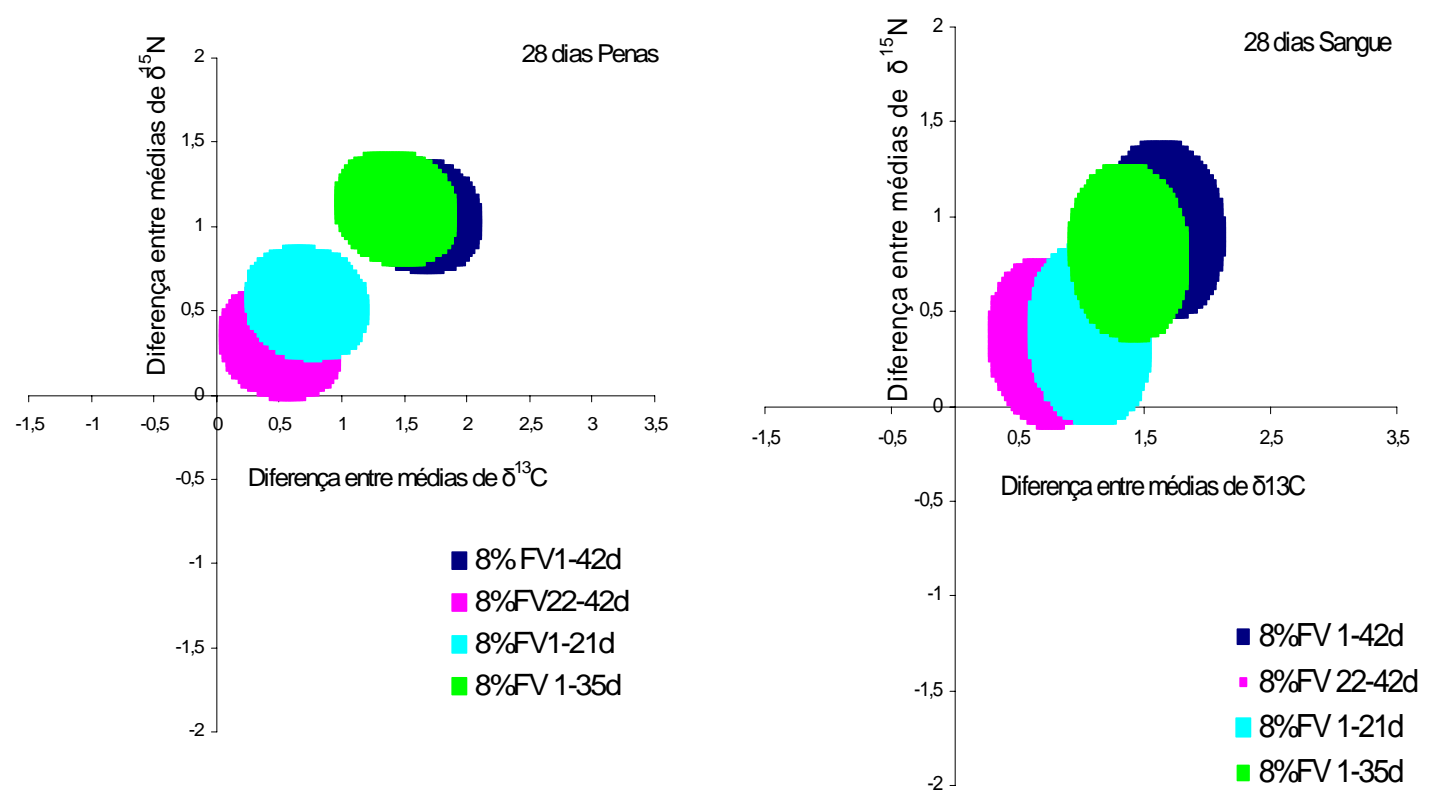

FIGURA 5. Regiões de confiança formadas pela diferença entre os valores isotópicos de $\delta^{13} \mathrm{C}$ e $\delta^{15} \mathrm{~N}$ de penas e sangue de frangos de corte aos 28 dias de idade de cada tratamento quando comparados ao tratamento controle. 
Na Figura 5 aos 28 dias, para as penas, as aves dos tratamentos FV1-42d, FV121d e FV1-35d diferiram das aves do tratamento vegetal (RV1-42d), pois suas regiões de confiança não sobrepuseram nenhum dos eixos no gráfico e, para as aves do tratamento FV22-42d que trocou a dieta vegetal por dieta com 8\% de FV após 21 dias, estes 7 dias de consumo não foram suficientes para incorporar o sinal isotópico da nova alimentação. Para o sangue, as aves do tratamento que recebeu dieta com $8 \%$ de FV durante todo o período experimental (FV1-42d) e as aves do tratamento FV1-35d diferiram do tratamento vegetal. Para as aves do tratamento FV1-21d, onde as aves permaneceram sob dieta com inclusão de $8 \%$ de FV passando para dieta vegetal aos 22 dias, este período de 7 dias foi suficiente para incorporar o sinal isotópico da dieta vegetal no sangue.

Para as aves do tratamento FV22-42d, que começaram a comer dieta com 8\% de farinha de vísceras aos 22 dias de idade, este período de 7dias não foi suficiente para troca de sinal, ou seja, o sinal não diferiu do tratamento vegetal. Oliveira (2005) também observou que 7 dias não foram suficientes para alterar o sinal isotópico em análises de músculo peitoral, quilha e tíbia de frango de corte.

Na Figura 6, aos 35 dias de idade, quando se analisaram as penas e o sangue, verificou-se que as aves dos tratamentos FV1-42d, FV22-42d e FV1-35d diferiram do tratamento vegetal, pois suas regiões de confiança não sobrepuseram nenhum dos eixos no gráfico. As aves do tratamento FV1-21d não diferiu das aves do tratamento vegetal, nem para penas nem para sangue, pois suas elipses se sobrepuseram ao eixo, de onde se conclui que 14 dias da troca da dieta foram suficientes para tornar o sinal igual ao da dieta vegetal, para as penas sendo que no sangue já havia se manifestado no período de 28dias. Estes resultados são semelhantes aos encontrados por Oliveira (2005) que avaliou o sinal isotópico de carbono e nitrogênio no músculo peitoral, na quilha e na tíbia de frangos de corte, recebendo uma dieta contendo farinha de vísceras em substituição a dieta vegetal, e verificou que o período de 14 dias foi suficiente para incorporar o sinal isotópico da nova dieta nestes tecidos.

Na Figura 7 aos 42 dias, para as penas e sangue, observa-se que as aves dos tratamentos FV1-42d, FV22-42d e FV1-35d diferiram do tratamento vegetal, pois suas regiões de confiança não sobrepuseram nenhum dos eixos no gráfico. As aves do tratamento FV35-42d, no qual as aves ingeriram dieta com farinha de vísceras por um 
período de 7 dias, observa-se que este período não foi suficiente para incorporar o sinal isotópico da alimentação nas penas e no sangue. As aves do tratamento FV1-21d, que receberam apenas a dieta com $8 \%$ de FV até 21 dias, também não diferiram das aves do tratamento vegetal (RV1-42d), pois aos 35 dias de idade, esta alteração de sinal já havia se manifestado (Figura 6).

Cruz et al. (2008) ao analisarem o fígado de frango de corte aos 42 dias de idade que consumiram farinha de vísceras até 21 dias idade (FV1-21 dias) verificaram assinatura isotópica semelhante às aves do grupo controle (dieta vegetal), não detectando o uso da farinha de vísceras na alimentação destas aves pela análise isotópica do fígado. De forma que, devido ao rápido turnover deste tecido, este não seria um bom indicador nestas condições. Já no caso das penas e sangue, os sinais isotópicos encontrados na presente pesquisa permitiram a detecção, em aves abatidas aos 42 dias, das aves que consumiram FV até 21 dias.
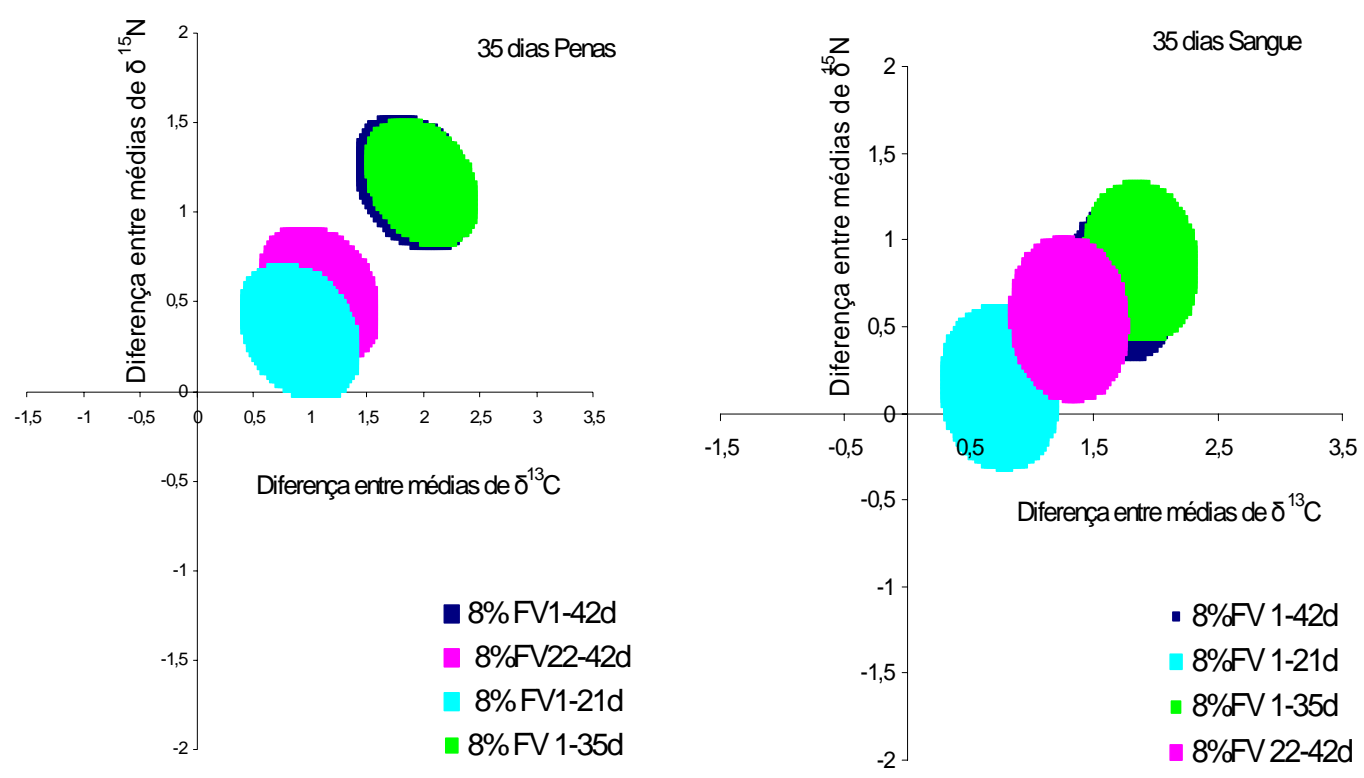

FIGURA 6. Regiões de confiança formadas pela diferença entre os valores isotópicos de $\delta^{13} \mathrm{C}$ e $\delta^{15} \mathrm{~N}$ de penas e sangue de frangos de corte aos 35 dias de idade de cada tratamento quando comparados ao tratamento controle. 


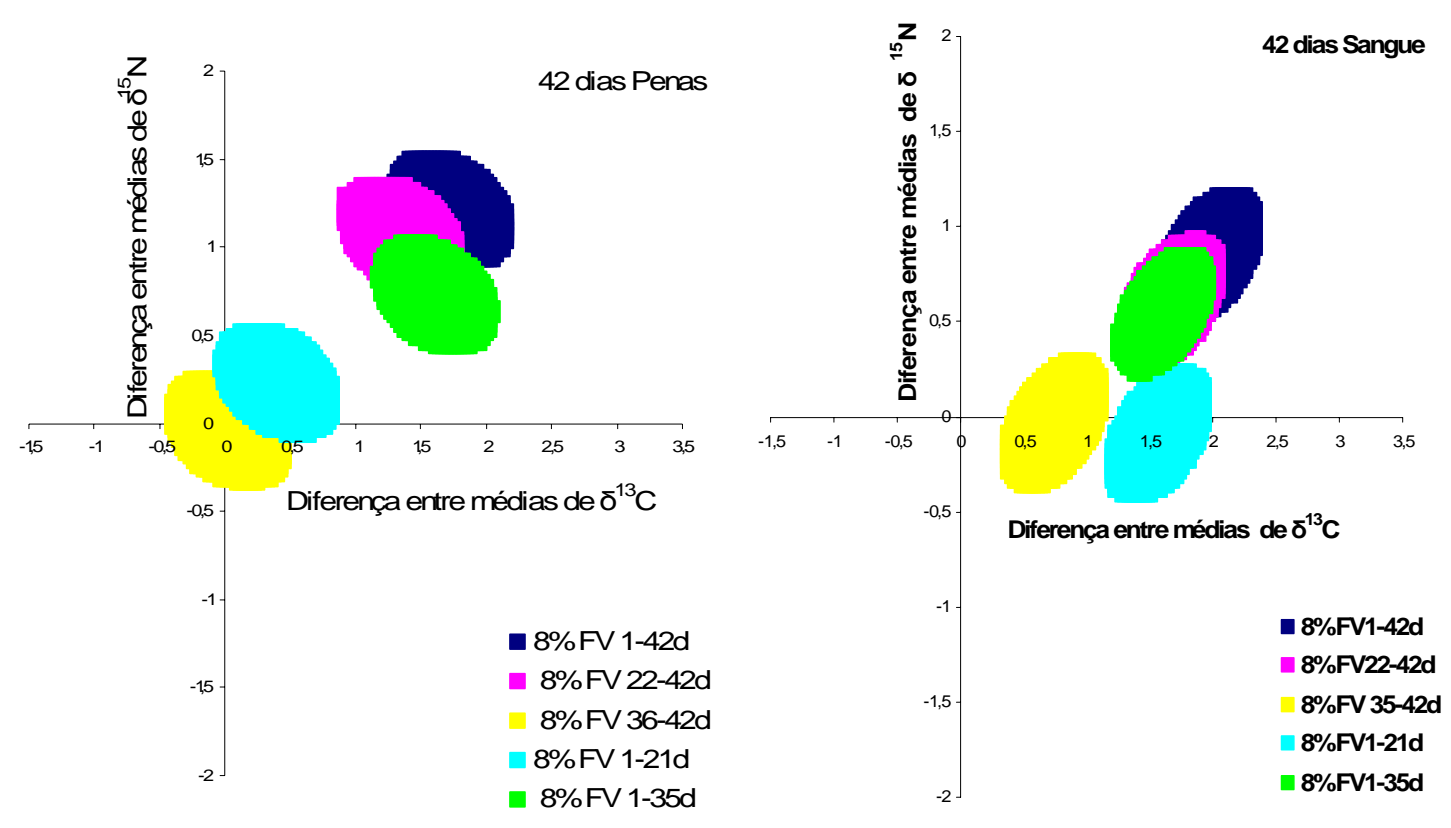

FIGURA 7. Regiões de confiança formadas pela diferença entre os valores isotópicos de $\delta^{13} \mathrm{C}$ e $\delta^{15} \mathrm{~N}$ de Penas e Sangue de frangos de corte aos 42 dias de idade de cada tratamento quando comparados ao tratamento controle.

O sangue foi à fração que melhor e mais rápido detectou as inclusões das farinhas de vísceras, devido ao maior distanciamento das elipses de confiança em relação aos eixos do gráfico, o que tornou possível rastrear esse ingrediente em frango de corte. $\mathrm{O}$ período de 7 dias foi suficiente para rastrear a utilização de farinha de vísceras na alimentação de frangos de corte, quando a idades das aves é de 7 dias, a partir do crescimento destas, somente o período de 14 dias foi suficiente para rastrear a utilização de farinha de vísceras sob a técnica dos isótopos estáveis. Resultados de pesquisas indicam que os tecidos podem ter pools de carbono com turnover rápido ou lento e, de modo geral, os tecidos mais ativos metabolicamente como sangue, fígado, pâncreas e têm taxas de turnover mais rápidas que os tecidos menos ativos, tais como os ossos e o tecido conjuntivo.

Apesar de o sangue ser um tecido mais ativo metabolicamente em comparação a outros tecidos, quando a ave está em crescimento é provável que a taxa de movimentação do carbono entre estes tecidos seja muito semelhante, embora cada tecido de um mesmo animal possa apresentar particular assinatura isotópica, fator de fracionamento e turnover isotópico (HOBSON \& CLARK, 1992). O efeito observado de diferentes taxas de crescimento entre os tecidos é o resultado da mudança nas 
propriedades básicas do metabolismo de cada um deles. Em condições normais, a chegada da maturidade corporal causa redução na taxa de síntese e aumento na taxa de degradação das proteínas, reduzindo a deposição de proteína corporal, e conseqüentemente diminuindo a taxa de crescimento (Cyrino, 1995). Nas aves a taxa de crescimento diário é acelerada até por volta do $35^{\circ}$ dia de vida, depois ocorre crescimento linear durante a puberdade, e essa taxa começa a declinar gradualmente a partir do $45^{\circ}$ dia, quando o animal atinge o peso corporal adulto (Lawrence \& Fowler, 2002).

Tecidos como o sangue e penas, de mais rápida e lenta alteração do sinal isotópico em função da dieta, respectivamente, podem compor estratégias de amostragem sem necessidade de sacrifício das aves e de fácil aplicação, em pontos críticos de controle nas empresas avícolas, servindo de ferramenta de apoio às auditorias e certificação de criações de frangos isentas de proteínas de origem animal na dieta.

\section{Conclusões}

Sob as condições experimentais, pode-se concluir que a aplicação da técnica dos isótopos estáveis de carbono e nitrogênio em penas de frango de corte pode detectar a utilização de farinha de vísceras na alimentação de frangos de corte por um período de até 21 dias após a retirada desse ingrediente da dieta, ou após 21 dias da inclusão da FV na dieta. No sangue, o período máximo para detecção do uso da farinha de vísceras na dieta dos frangos é menor, de apenas 7 dias para frangos na fase inicial de criação, em função da elevada taxa de crescimento, e de 14 dias para frangos em crescimento. 


\section{Referências Bibliográficas}

BLOCK JUNIOR, C. Monitoramento da qualidade de rações brasileiras para ruminantes por espectrometria de massa. In: SIMPÓSIO SOBRE MANEJO E NUTRIÇÃO DE AVES E SUÍNOS E TECNOLOGIA DA PRODUÇÃO DE RAÇÕES, 2002, Campinas. Anais... Campinas: Colégio Brasileiro de Nutrição Animal, p.251-252. 2002.

BRICOUT, J.; KOZIET, J. Control of the authenticity of orange juice by isotopic analysis. Journal of Agricultural Food Chemistry, v.35, p.758-760, 1987.

BROOKES, S. T.; BARRIE, A.; DAVIES, J. E. A rapid ${ }^{13} \mathrm{C} /{ }^{12} \mathrm{C}$ test for determination of corn-syrups in honey. Journal of the Association of Official Analytical Chemists, v.74, p.627-629, 1991.

CIMA, E.G; AMORIM, L. S. B.; SHIKIDA, P. F. A. A importância da rastreabilidade para o sistema de segurança alimentar na industria avícola. Revista FAE, Curitiba, v.9, n.1, p.1-12. 2006.

CHOI, W.J.; LEE, S.M.; RO, H.M.; KIM, K.C.; YOO, S.H. Natural ${ }^{15} \mathrm{~N}$ abundances of maize and soil amended with urea and composted pig manure. Plant and Soil, v.245, p.223-232, 2002.

CRUZ, V.C.; SANTOS, G.S.; DUCATTI, C.; SARTORI, J.R.; ARAUJO, P.C.; STRADIOTTI, A.C. Rastreabilidade de farinha de origem animal no fígado de frangos de corte usando a técnica dos isótopos estáveis de carbono $\left({ }^{13} \mathrm{C} /{ }^{12} \mathrm{C}\right)$ e nitrogênio $\left({ }^{15} \mathrm{~N} /{ }^{14} \mathrm{~N}\right)$. In: $45^{\circ}$ Reunião Anual da Sociedade Brasileira de Zootecnia; Lavras; Anais... Lavras, MG -UFLA, p.1-4, 2008.

CYRINO, J.E.P. Regulação nutricional do crescimento. In: Simpósio Internacional sobre Nutrição de Peixes e Crustáceos, p.69-90, 1995. 
DeNIRO, M.J.; EPSTEIN, S. You are what you eat (plus a few \%o) the carbon isotope cycle in food chains. Geological Society of America, v. 6, p. 834 (Abstract), 1976.

DeNIRO, M.J.; EPSTEIN, S. Influence of diet on the distribution of carbon isotopes in animals. Geochimica et Cosmichimica Acta, London, v.42, p.495-506, 1978.

HANDLEY, L.L., RAVEN, J.A. The use of natural abundance of nitrogen isotopes in plant physiology and ecology. Plant, Cell and Environment, v.15, p.965-985, 1992.

HOBSON, K.A.; CLARK, R.G. Assessing avian diets using stable isotopes I: Turnover of 13C in tissues. The Condor, v.94, p.181-188, 1992a.

KELLY, S.; PARKER, I.; SHARMAN, M.; DENNIS, J.; GOODALL, I. Assessing the authenticity of single seed vegetable oils using fatty acid stable carbon isotope ratios $\left({ }^{13} \mathrm{C} /{ }^{12} \mathrm{C}\right)$. Food Chemistry, v.59, n.2, p.181-186, 1997.

KOHL, D.H.; SHEARER, G. Isotopic fractionation associated with symbiotic $\mathrm{N}_{2}$ fixation and uptake of $\mathrm{NO}_{3}{ }^{-}$by plants. Plant Physiology, v.66, p.51-56, 1980.

KOZIET, J.; ROSSMANN, A.; MARTIN, G. J.; ASHURST, P. R. Determination of carbon-13 content of sugars of fruit and vegetable juices. Analytica Chimica Acta, v.271, p.31-38, 1993.

LAWRENCE, T.L.J.; FOWLER, V.R. Growth and Puberty in Breeding Animals. In: Growth of Farm Animals - Second Edition, v.13, p.271, 2002.

MANCA, G.; CAMIN, F.; COLORU, G.; Del CARO, A.; DETENTORI, D.; FRANCO, M. A.; VERSINI, G. Characterization of the geographical origin of Pecorino Sardo cheese by casein stable isotope $\left({ }^{13} \mathrm{C} /{ }^{12} \mathrm{C}\right.$ and $\left.{ }^{15} \mathrm{~N} /{ }^{14} \mathrm{~N}\right)$ ratios and free amino acid ratios. Journal of Agricultural Food Chemistry, v.49, p.1404-1409, 2001. 
MARTIN, G. J.; GUILlOU, C.; MARTIN, M. L.; CABANIS, M. T.; TEP, X.; AERNY, J. Natural factors of isotope fractionation and the characterization of wines. Journal of Agricultural Food Chemistry, v.36, p.316-322, 1988.

OLIVEIRA, R. P. Rastreabilidade da farinha de vísceras de aves na alimentação de frangos de corte pela técnica dos isótopos estáveis $\left.\left({ }^{13} \mathrm{C} /{ }^{12} \mathrm{C} \mathrm{e}{ }^{15} \mathrm{~N} /{ }^{14} \mathrm{~N}\right)\right) .2005 .109 \mathrm{f}$ Tese. (Doutorado em Zootecnia) - Faculdade de Medicina Veterinária e Zootecnia, Universidade Estadual Paulista, Botucatu.

RASTREABILIDADE e CERTIFICAÇÃO: Um modelo de etapas para implantação de um sistema nacional para rastreabilidade na cadeia de produção de aves. Revista Avicultura Industrial, Porto Feliz, ano 95, n.3, ed. 1121, 2004. Disponível em:< http://www.aviculturaindustrial.com.br> Acesso em 06 set. 2009.

ROSSMANN, A.; HABERHAUER, G.; HOLZL, S.; HORN, P.; PICHLMAYER, F.; VOERKELIUS, S. The potential of multielement stable isotope analysis for regional origin assignment of butter. European Food Research \& Technology, v.211, p.32-40, 2000.

ROSTAGNO, H. S.; ALBINO, L. F. T.; DONZELE, J. L.; GOMES, P. C.; OLIVEIRA, R. F.; LOPES, D. C.; FERREIRA, A. S.; BARRETO, S. L. T. Tabelas brasileiras para aves e suínos: composição de alimentos e exigências nutricionais. Viçosa: UFV, 2005. 186p.

SAS Institute. SAS (STATISTICAL ANALYSIS SYSTEM). User’s Guide: Statistics, Cary: SAS Institute, 2000. 1 CD-ROM.

SILVA, I. J. O. A rastreabilidade dos produtos agropecuários do Brasil destinados à exportação. In: XII CURSO DE RASTREABILIDADE NA PRODUÇÃO ANIMAL BRASILEIRA, 2004, Piracicaba. Anais... Piracicaba: NUPEA/ESALQ-USP, 2004. 
SLEIMAN, M.; DUCATTI, C.; VENTURINI FILHO, W. G.; SILVA, E. T. Isotopic analysis of carbon (13C/12C) and nitrogen $(15 \mathrm{~N} / 14 \mathrm{~N})$ performed in raw material used for pilsen beer brewing. In: V BRAZILIAN MEETING ON CHEMISTRY OF FOODS AND BEVERAGES; 2004; São Carlos. Anais... São Carlos: Instituto de Química de São Carlos - USP; 2004. p.1-4.

VOGEL, J.C. Variability of carbon isotope fractionation during photosynthesis. In: Ehleringer, J.R., Hall, A.E., Farquhar, G.D., editores. Stable isotopes and plant carbonwater relations. San Diego: Academic Press Inc.; 1993. p.29-46.

WERNER, R.A.; SCHMIDT, H.L. The in vivo nitrogen isotope discrimination among organic plant compounds. Phytochemistry, v.61, p.465-484, 2002.

WHITE, J. W.; WINTERS, K.; MARTIN, P.; ROSSMANN, A. Stable carbon isotope ratio analysis of honey: validation of internal standard procedure for worldwide application. Journal of the Association of Official Analytical Chemists International, v.81, p.610-619, 1998. 
CAPITULO 3 


\section{IMPLICAÇÕES}

A rastreabilidade de farinhas de origem animal na alimentação de frangos de corte, por meio da variação natural dos isótopos estáveis de carbono e nitrogênio, se mostrou promissora, diante de estudos realizados no Centro de Isótopos Estáveis/IBB/UNESP Campus de Botucatu. Estas pesquisas surgiram da necessidade de uma tecnologia independente para a certificação de frangos de corte que não fossem alimentados com produtos de origem animal, visto a exigência de mercados importadores dessas aves.

Considerando os resultados obtidos neste trabalho, novos estudos poderão aprofundar ainda mais esta linha de pesquisa, não utilizando apenas o sangue total, mas do plasma que pode fornecer informações em mais curto prazo e expressar sinais dietéticos de novas dietas, já que o plasma é o responsável por transportar substâncias dissolvidas, tais como nutrientes.

A utilização de penas de frango de corte mostrou ser bom tecido para rastrear a utilização de farinha de vísceras na alimentação de frangos de corte em dietas contendo esse ingrediente faz parte da alimentação em alguma fase de criação, podendo compor estratégias de amostragem sem necessidade de sacrifício das aves e de fácil aplicação, servindo de ferramenta de apoio as empresas certificadoras de criações de frangos isentas de proteínas de origem animal na dieta.

Novas pesquisas devem ser realizadas com o objetivo de aprimorar a técnica dos isótopos estáveis nas penas, podendo utilizar não somente as penas dos machos, mas também das fêmeas, para verificar se o sexo pode influenciar a detecção de farinhas de origem animal na alimentação. Seria indicado também coletar as penas das asas por serem as primeiras a crescerem. 